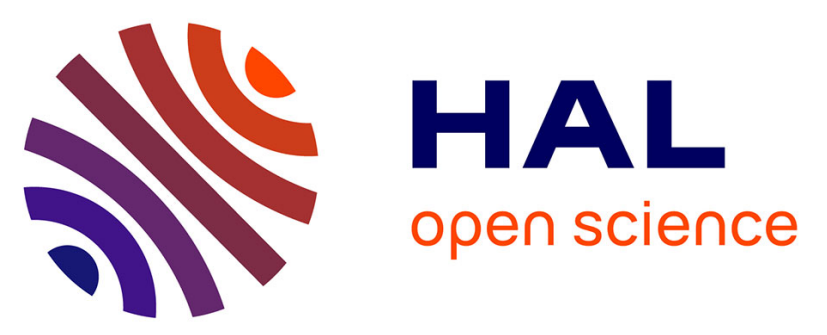

\title{
Are restored side channels sustainable aquatic habitat features? Predicting the potential persistence of side channels as aquatic habitats based on their fine sedimentation dynamics
}

Jérémie Riquier, Hervé Piégay, Nicolas Lamouroux, Lise Vaudor

\section{To cite this version:}

Jérémie Riquier, Hervé Piégay, Nicolas Lamouroux, Lise Vaudor. Are restored side channels sustainable aquatic habitat features? Predicting the potential persistence of side channels as aquatic habitats based on their fine sedimentation dynamics. Geomorphology, 2017, 295, pp.507-528. 10.1016/j.geomorph.2017.08.001 . hal-01575564

\author{
HAL Id: hal-01575564 \\ https://hal.science/hal-01575564
}

Submitted on 31 Jan 2020

HAL is a multi-disciplinary open access archive for the deposit and dissemination of scientific research documents, whether they are published or not. The documents may come from teaching and research institutions in France or abroad, or from public or private research centers.
L'archive ouverte pluridisciplinaire HAL, est destinée au dépôt et à la diffusion de documents scientifiques de niveau recherche, publiés ou non, émanant des établissements d'enseignement et de recherche français ou étrangers, des laboratoires publics ou privés. 


\section{Reference:}

Riquier J., Piégay H., Lamouroux N., Vaudor L. (2017). Are restored side channels sustainable aquatic habitat features? Predicting the potential persistence of side channels as aquatic habitats based on their fine sedimentation dynamics. Geomorphology, 295: 507-528.

\section{Edited manuscript available at:}

https://doi.org/10.1016/j.geomorph.2017.08.001 
$1 \quad$ Are restored side channels sustainable aquatic habitat features? Predicting

2 the potential persistence of side channels as aquatic habitats based on their

3 fine sedimentation dynamics

4

5 Jérémie Riquier ${ }^{\mathrm{a},}{ }^{*}$, Hervé Piégay $^{\mathrm{a}}$, Nicolas Lamouroux ${ }^{\mathrm{b}}$, Lise Vaudor ${ }^{\mathrm{a}}$

6 a Université de Lyon, CNRS, UMR 5600 - Environnement-Ville-Société, Site ENS de Lyon, Lyon,

7 France

$8 \quad \mathrm{~b}$ IRSTEA - UR MALY, Villeurbanne, France

9

10 * Corresponding author: Jérémie Riquier, CNRS UMR 5600 - ENS de Lyon - 15, parvis René 11 Descartes - BP 7000 - 69342 Lyon Cedex 07, France. E-mail: jeremie.riquier@gmail.com. 


\section{Abstract}

The restoration of side channels (also referred to as abandoned channels, former channels, floodplain channels, or side arms) is increasingly implemented to improve the ecological integrity of riverfloodplain systems. However, the design of side channel restoration projects remains poorly informed by theory or empirical observations despite the increasing number of projects. Moreover, feedback regarding the hydromorphological adjustment of restored channels is rarely documented, making it difficult to predict channel persistence as aquatic habitats. In this study, we analyze the spatial and temporal patterns of fine sediment deposition $(<2 \mathrm{~mm})$ in 16 side channels of the Rhône River, France, restored in 1999-2006 by a combination of dredging and/or partial to full reconnection of their extremities and as a by-product of an increase in minimum flow through the bypassed main channels. We develop prediction tools to assess the persistence of restored channels as aquatic habitats, using between five and seven monitoring surveys per channel (spanning 7-15 years after restoration). Observed channel-averaged sedimentation rates ranged from 0 to $40.3 \mathrm{~cm} \cdot \mathrm{y}^{-1}$ and reached $90.3 \mathrm{~cm} \cdot \mathrm{y}^{-1}$ locally. Some channels exhibited a significant decline of sedimentation rates through time, whereas others maintained rather constant rates. Scouring processes (i.e., self-rejuvenation capacity) were occasionally documented in 15 channels. Six of the 16 studied channels appeared to be self-sustaining. The 10 others accumulated more and more fine sediment deposits after restoration. Parametric modeling of sedimentation rates suggested that among these 10 channels, four have long life-durations (i.e., more than a century), three have intermediate life-durations (i.e., likely between three and nine decades), and three others have short life-durations (i.e., likely between two and five decades). Observed channel-averaged sedimentation rates can be predicted from the frequency and magnitude (i.e., maximum shear stress) of upstream overflow events and the maximum intensity of backflow events (i.e., maximum backflow capacity). These predictors reflect the dominant role of side channel geometry (i.e., morphology of the upstream alluvial plug, slope conditions) in controlling their flooding regime. These models applied successfully to a wide range of channel morphologies and can be used to quantify a priori the likely effects and the sustainability of side channel restoration. 
Keywords: channel design; floodplain restoration; floodplain sedimentation; hydrological connectivity; riverine wetland

\section{Introduction}

Side channels (e.g., secondary side channels, backwater channels, sloughs, oxbow lakes) are ubiquitous landforms of shifting river channels. Two major phases govern the geomorphic evolution of these channels from aquatic to terrestrial stages: an initial bedload infilling followed by longer term fine sediment deposition. This sequence, established initially for meander cutoffs (e.g., Gagliano and Howard, 1984; Constantine et al., 2010; Toonen et al., 2012), also applies to channelized reaches of former multi-branched river-floodplain systems, where side channels were isolated from the main channel with submersible longitudinal dykes.

In the early stages (i.e., following cutoff or avulsion processes), active side channels are permanently connected with another river segment at both extremities. They can transport and trap bedload material until the establishment of an alluvial plug, which usually occurs at the upstream end. The establishment of a plug is not inevitable. For example, active side channels can sometimes maintain their permanent upstream connection with another river segment as stable bifurcation (e.g. Kleinhans et al., 2013) or an engineered bottom sill can prevent bedload entering the intake and thus plug formation (e.g. Simons et al., 2001). The angle of diversion of the flow separating the main channel and the cutoff channel is a critical factor in explaining plug establishment (Gagliano and Howard, 1984; Shields and Abt, 1989; Piégay et al., 2002; Constantine et al., 2010; Dieras, 2013). When compared to low diversion angles (e.g., chute cutoffs), high angles (e.g., neck cutoffs) often promote lower shear stresses and a quick establishment of an upstream sediment plug, which in turn results in less bedload transport in the cutoff inducing shorter plugs and a greater remnant water volume after the disconnection (Constantine et al., 2010). Plug establishment in meander cutoffs can take from a few months to about a decade (Gagliano and Howard, 1984; Hooke, 1995; Gautier et al., 2007; Dieras, 2013). In many channelized rivers, where formerly active side channels were artificially disconnected from the main river channel at their upstream end and sometimes at both ends by the 
establishment of submersible longitudinal dykes (e.g., Hohensinner et al., 2014 - Danube, Austria), this first stage is usually curtailed and a second stage (discussed below) would then be much longer (Dépret et al., in press).

Once disconnected from the main channel at low flow at their upstream end, backwater channels are progressively filled by fine-grained material (from sand to clay) and gradually evolve into terrestrial environments. Their persistence as aquatic habitats is then mainly a function of fine sediment deposition rates driven by allogenic successional processes. Channel-averaged rates reported in the literature range from $0 \mathrm{~cm} \cdot \mathrm{y}^{-1}$ in a former braided channel of the Rhône River (Citterio and Piégay, 2009) to $18 \mathrm{~cm} \cdot \mathrm{y}^{-1}$ in an oxbow lake of the Sacramento River (Stella et al., 2011). Several important controls can explain these differences, including sediment concentration, trapping efficiency, and scouring capacity of the channel. These last two factors are significantly affected by side channel geometry.

Differences in geometry can be linked to cutoff types or types of channel abandonment. Sedimentation rates can vary according to the geomorphologic origin of side channels (Piégay et al., 2000, 2008; Citterio and Piégay, 2009), which is inherited from the fluvial dynamics during cutoff (e.g., slope conditions, depth, width). For example, former braided channels often experience lower rates than abandoned meanders because they have a steeper slope and a lower hydraulic capacity. Dieras (2013) estimated that meander chute cutoffs filled about 10 times faster than meander neck cutoffs, primarily because the remnant aquatic area after the establishment of the plug was already very low in chute cutoffs so that they are quickly filled with fine material. Similarly, Dépret et al. (in revision) demonstrated that artificially abandoned side channels in the Rhône River (i.e., closed with submersible dykes at their upstream end) have a much longer persistence in comparison to natural side channels that were disconnected by a sediment plug. Indeed, the artificial and imposed premature closing of their upstream end by submersible dykes has truncated the initial bedload infilling phase of the side channels.

Side channel fine sediment deposition rates evolve through time according to their flooding regime, that is, the frequency and magnitude with which upstream overflow events (i.e., lotic functioning) and backflow events (i.e., passive inundation of channels from their downstream end) 
occur. Upstream overflow events reflect the potential of fine sediment scouring and backflow events reflect the potential for fine sediment deposition (Citterio and Piégay 2009). Fine sediment deposition rates also decrease quickly in intensity through time as a result of plug(s) accretion and/or overall side channel accretion (Hooke, 1995; Gautier et al., 2007; Kondolf and Stillwater Sciences, 2007; Riquier, 2015).

Once fully isolated from the main channel, allogenous processes are gradually replaced by autogenous ones (e.g., internal production of organic matter) and depositional infilling occurs at lower rates (Bravard et al., 1986; Rostan et al., 1987; Reckendorfer et al., 2013). Morphodynamic processes in the main channel (degradation/aggradation or contraction/enlargement) influence fine sediment deposition rates in side channels by decreasing or increasing their trapping efficiency, their scouring capacity, and/or directly affecting water depth in side channels independently of fine sediment accumulation through base level changes (Bravard et al., 1997; Piégay et al., 2000, 2008; Riquier, 2015). As a consequence, the persistence of side channels as aquatic habitats has previously been shown to vary between a few years and several centuries (Gagliano and Howard, 1984; Amoros et al., 2000; Constantine et al., 2010; Dieras, 2013).

Over recent decades, numerous projects involving side channel restoration have been implemented to improve the ecological functioning of highly regulated river-floodplain systems (e.g., Theiling, 1995 - upper Mississippi, USA; Reckendorfer et al., 2005 - Danube, Austria; Simons et al., 2001- Rhine, Netherlands; Baptist et al., 2004 - Waal and Rhine, Netherlands; Jacobson and Galat, 2006 - lower Missouri, USA; Stammel et al., 2012 - upper Danube, Deutschland; Lamouroux et al., 2015 - upper and middle Rhône, France). However, designs for side channel restoration projects are poorly informed by theory or empirical observations, despite massive investments (Jacobson et al., 2004; Shields et al., 2009). Only a few studies have reported detailed hydromorphological responses of side channel restoration (Jacobson et al., 2001, 2004; Amoros et al., 2005). Consequently, the development of practical predictive tools to promote effective side channel restoration remains a major challenge. 
In this study, we analyzed fine sedimentation dynamics in 16 restored side channels of the Rhône River (France) to (i) describe and classify sedimentation patterns and rates; (ii) model the accumulation dynamics of observed fine sediment deposition; (iii) model the influence on sedimentation rates of quantitative descriptors of the flooding regime of channels that managers can modify; and (iv) provide estimates of the potential persistence of restored side channels as aquatic habitats.

\section{Materials and methods}

\subsection{Study sites}

Over the past two centuries, the cumulative effects of human actions (e.g., embankment construction, dam building) have deeply affected the physical and ecological integrity of the Rhône river-floodplain system (Roux et al., 1989; Olivier et al., 2009). A large restoration project started in the late 1990s to recover the diversity of floodplain habitats and communities (Lamouroux et al., 2015). Between 1999 and 2006, 24 side channels were restored in four different reaches of the Rhône River that are bypassed by hydropower plants. Three of these reaches were located in the French upper Rhône (Chautagne, Belley, and Brégnier-Cordon; Fig. 1) and one in the middle course of the river, just downstream of Lyon (Pierre-Bénite). Restored side channels were dredged, either locally or over their entire lengths, with or without upstream and/or downstream plug removal, in order to increase the volume of aquatic habitats and to improve groundwater-channel exchanges (Riquier et al., 2015). In addition, minimum regulated flows were increased in the bypassed main channels, sometimes influencing water levels in the side channels (Lamouroux et al., 2015). Of the 16 restored channels monitored (see Table 1 for a list of the selected side channels and Fig. 1 for maps), five were active side channels with permanent upstream and downstream surface connections after restoration (100\%

144 flow exceedance) and 11 were backwater channels with permanent connections at their downstream

145 ends only (i.e., plugged at their upstream ends, but they do pass water and sediment with some range 146 of exceedance frequency; for details of restoration works, see Lamouroux et al., 2015 and Riquier et 147 al., 2015). 
The hydrology of the main river channels varied among the four studied reaches (Fig. 2)

149 depending on the management of dams. In the Rhône, each bypassed reach includes a diversion dam

150 that redirects flow into an artificial canal that feeds a hydroelectric power plant (see Figs. 1B and 1C).

151 The old riverbed (so-called old Rhône, hereafter bypassed main channel or bypassed reach) receives a

152 minimum flow, except when it is used to evacuate floods that exceed the maximum operating flow of

153 the plant. Downstream of each power plant, the canal and the bypassed main channel merge to form

154 the total Rhône (i.e., reaches that have not been bypassed). Such hydropower bypass schemes highly

155 modify flood hydrograph characteristics (Klingeman et al., 1998). Most of the 16 side channels

156 depend on the hydrological regime of the four studied bypassed main channels (Table 1). However,

157 two of them have regimes depending on the total Rhône discharge (Fig. 2). As a consequence, side

158 channels are influenced by flow regimes that differ in term of flood magnitude, frequency, and timing.

159 In bypassed channels, from restoration date to the last survey, main high-flood events generally

160 occurred during the three years following restoration completion irrespective of their date of

161 restoration (Fig. 2). The highest flood occurred during the winter 2011-2012 at Belley. These events

162 ranged from the 5-year flood threshold in Belley to a 20-year flood in Pierre-Bénite. 

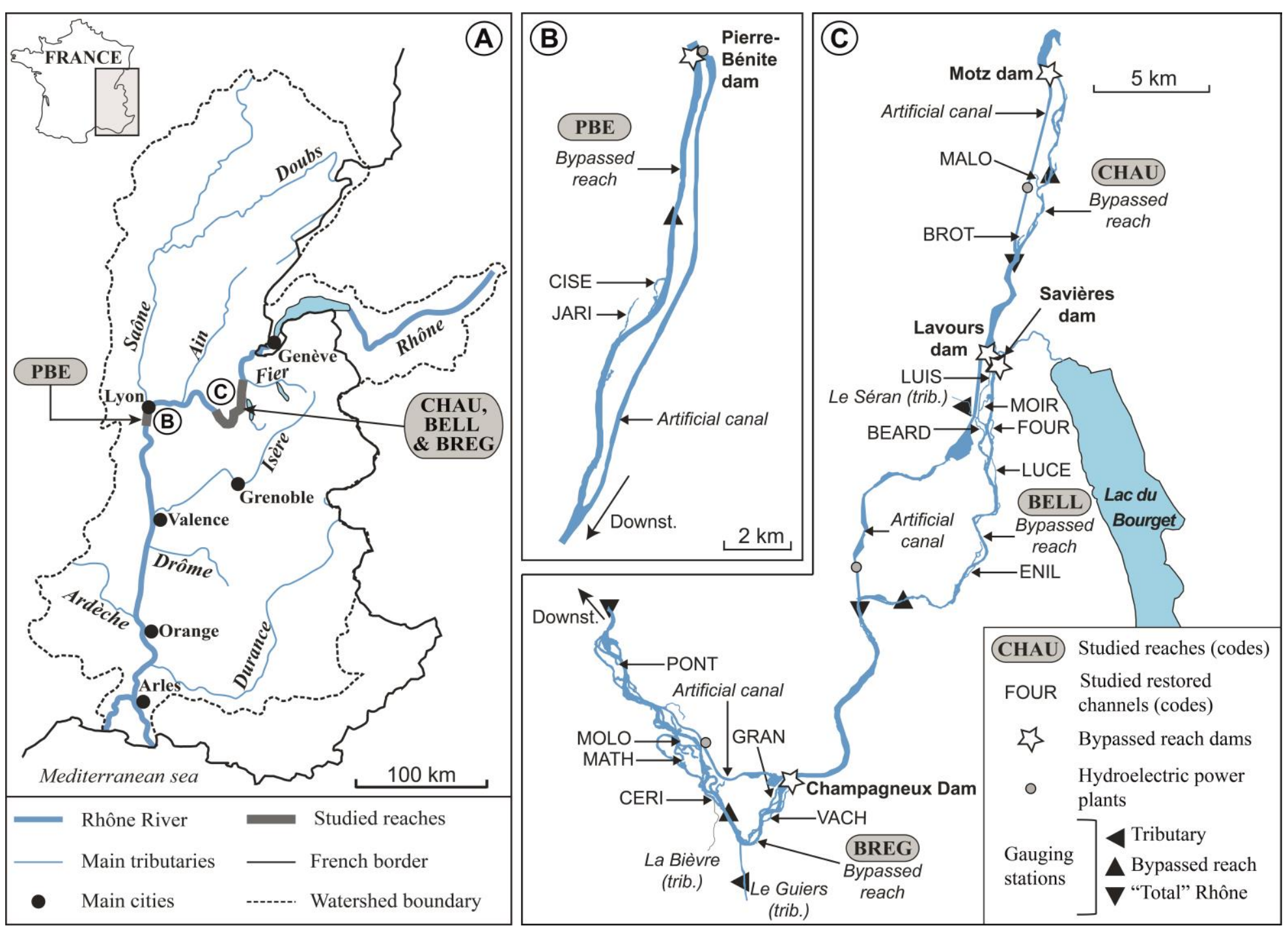

Fig. 1. (A) Location of studied reaches in the Rhône River watershed. Location of studied restored side channels in (B) Pierre-Bénite (abbreviated PBE) reach and (C) Chautagne, Belley, and Brégnier-Cordon reaches (abbreviated CHAU, BELL and BREG, respectively). See Table 1 for channel codes. Resources: BD 166 Carthage $\odot$ and BDT Rhône $\odot$, IGN. 

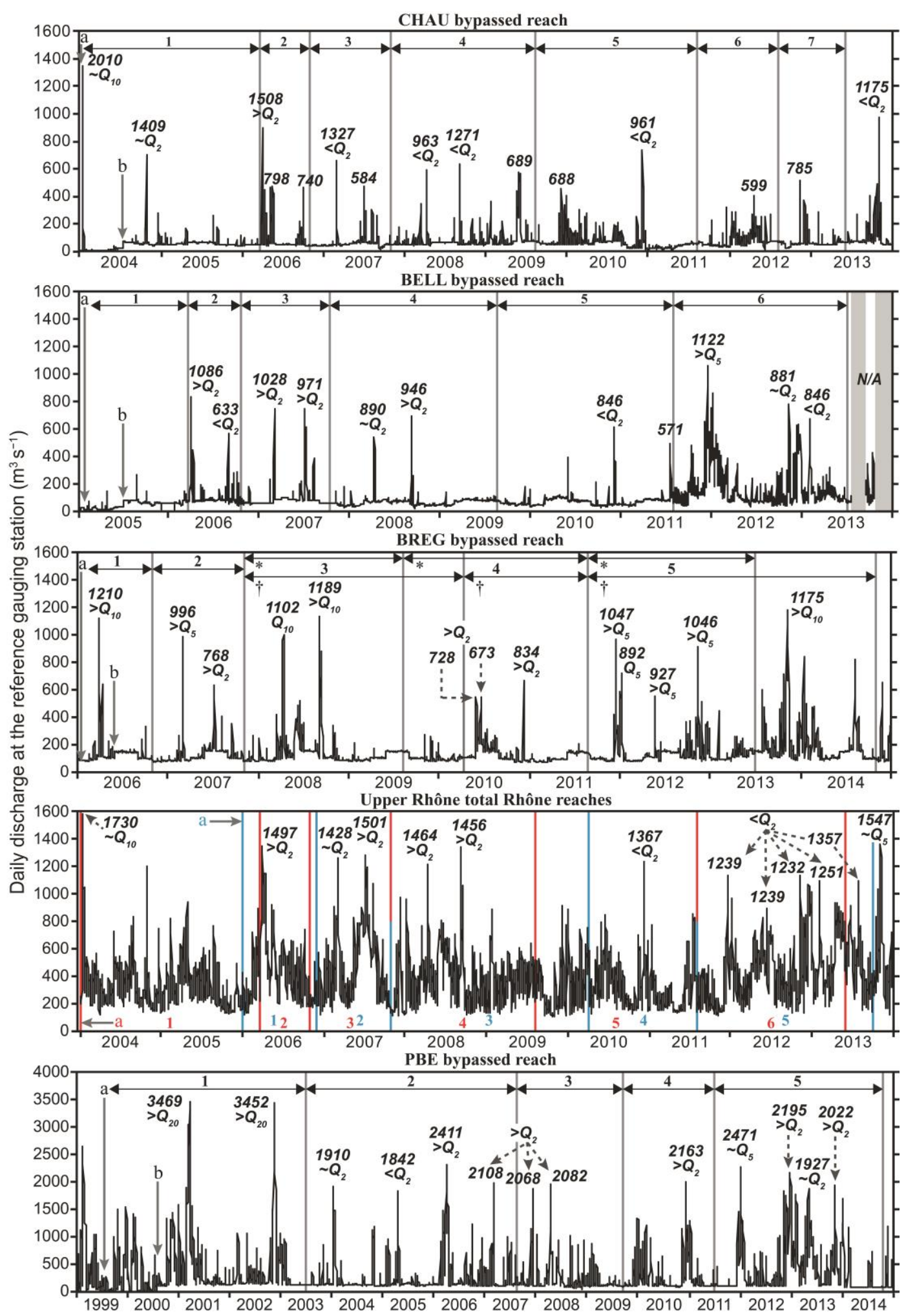

Fig. 2. Daily average discharge in the different reaches from restoration to the last surveys and identification of major flood events ( $Q x$ refers to an approximate return period of $x$ years). Maximum hourly discharges during floods are indicated (data from the Compagnie Nationale du Rhône). Periods between monitoring surveys are indicated for each reach above the discharge series. ' $a$ ' shows the end of civil engineering works and ' $b$ ' the increase of minimum flow. See Table 1 for the correspondence between bypassed reaches and side channels and for date of surveys. For BREG bypassed reach: (*) intersurvey periods relevant for GRAN and CERI channels; $(\dagger)$ periods relevant for VACH, MATH, and MOLO channels. The total discharge of the Rhône (here measured downstream of BELL reach, Fig. 1) illustrates the discharge history for the two side channels connected out of bypassed reaches (BROT restored in 2004 and PONT restored in 2006), although slight spatial variations were taken into account in our analyses. Vertical red lines and associated numbers depict intersurvey periods for BROT and blue lines are relevant for PONT. 


\subsection{Monitoring surveys and measured parameters}

We conducted five to seven monitoring surveys, ranging from a few months after restoration to 7-15 years after restoration, depending on the reach and the side channel considered (Table 1). In addition, a pre-restoration survey was performed in 12 of the 16 studied channels. For each survey and in each channel, we measured water depth and fine sediment thickness (i.e., deposits with the majority of particles $<2 \mathrm{~mm}$ ) along the channel centerline with a rod (Fig. 3). These measures were usually performed from a boat. We used a meter counter (namely a topofil, also known as a hip chain in North America) to measure the distance from a reference upstream point used for each of the surveys. Fine sediment thickness was calculated by subtracting local measures of water depth by local measures of total depth (i.e., depth down to the top of the coarse material reference layer observed before restoration or right after restoration works). Indeed, right after restoration, all side channels exhibited a well-defined reference surface made of gravel and cobble thanks to dredging operations. In this context and assuming that no gravel has been deposited post restoration, probing fine sediment thickness to refusal at the assumed reference surface is an accurate measure of net deposition. In order to minimize microtopography effects, we used averages of three to five repeated depth measures (hereafter, local measures) performed within an area of about $0.25 \mathrm{~m}^{2}$. For most post-restoration surveys, local measures of water depth and fine sediment thickness were performed every $10 \mathrm{~m}$ along the centerline of the channel length, providing between 19 and 164 local measures per channel (see e.g., Fig. 5 for an overview of the number of local measurements performed for each survey and each side channel). Before restoration, sampling efforts were limited to 10 sampling points regularly distributed along the whole side channel length. 


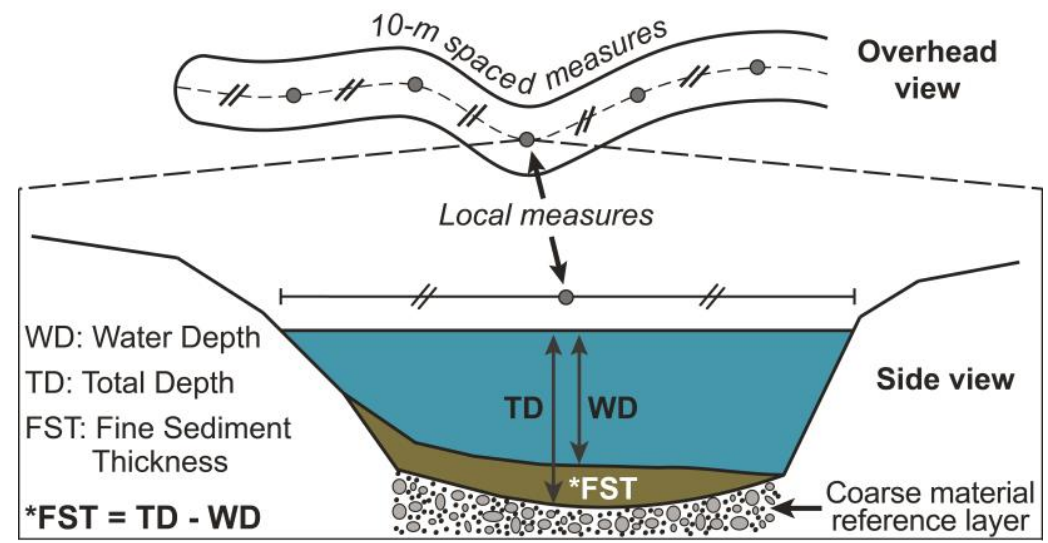

202 Fig. 3. Measures of water depth and fine sediment thickness. 
Table 1

Overview of reaches, side channels and date of available surveys; dark gray cells depict the year of restoration of each studied channel; slight grey cells show surveys performed before restoration (see Fig. 1 for location of studied reaches and side channels)

\begin{tabular}{|c|c|c|c|c|c|c|c|c|c|c|c|c|c|c|c|c|c|}
\hline \multicolumn{3}{|c|}{ Side channels } & \multirow{2}{*}{$\begin{array}{l}\text { Monitored length of } \\
\text { the waterbody }(\mathrm{m})\end{array}$} & \multirow{2}{*}{$\begin{array}{l}\text { Upstream plug } \\
\text { length }(\mathrm{m})\end{array}$} & \multicolumn{13}{|c|}{ Date of field surveys (time since restoration, in decimal years) } \\
\hline $\begin{array}{l}\text { Reach } \\
\text { code }^{a}\end{array}$ & Name & Code & & & 1999 & 2003 & 2004 & 2005 & $2006 a^{b}$ & $2006 b^{b}$ & 2007 & 2009 & 2010 & 2011 & 2012 & 2013 & 2014 \\
\hline CHAU & Malourdie $^{c}$ & MALO & 350 & 780 & - & - & Rest. & - & $\begin{array}{l}\text { Mar. } \\
(2.2)\end{array}$ & $\begin{array}{l}\text { Oct. } \\
(2.8)\end{array}$ & $\begin{array}{l}\text { Oct. } \\
(3.8)\end{array}$ & $\begin{array}{l}\text { Aug. } \\
(5.7)\end{array}$ & - & $\begin{array}{l}\text { Aug. } \\
(7.6)\end{array}$ & $\begin{array}{l}\text { Aug. } \\
(8.6)\end{array}$ & $\begin{array}{l}\text { Jun. } \\
(9.4)\end{array}$ & - \\
\hline CHAU & Brotalet $^{\mathrm{d}}$ & BROT & 650 & 130 & - & - & Rest. & - & $\begin{array}{l}\text { Mar. } \\
(2.1)\end{array}$ & $\begin{array}{l}\text { Oct. } \\
(2.7)\end{array}$ & $\begin{array}{l}\text { Oct. } \\
(3.7)\end{array}$ & $\begin{array}{l}\text { Aug. } \\
(5.6)\end{array}$ & - & $\begin{array}{l}\text { Aug. } \\
\text { (7.5) }\end{array}$ & - & $\begin{array}{l}\text { Jun. } \\
(9.4)\end{array}$ & - \\
\hline BELL & Luisettes $^{c}$ & LUIS & 460 & 60 & - & - & $\begin{array}{l}\text { May } \\
(0.8)\end{array}$ & Rest. & $\begin{array}{l}\text { Feb. } \\
(0.9)\end{array}$ & $\begin{array}{l}\text { Oct. } \\
(1.6)\end{array}$ & $\begin{array}{l}\text { Oct. } \\
(2.6)\end{array}$ & $\begin{array}{l}\text { Aug. } \\
(4.5)\end{array}$ & - & $\begin{array}{l}\text { Aug. } \\
(6.4)\end{array}$ & - & $\begin{array}{l}\text { Jun. } \\
(8.3)\end{array}$ & - \\
\hline BELL & Moiroud $^{c}$ & MOIR & 680 & 315 & - & - & $\begin{array}{l}\text { Apr. } \\
(0.9)\end{array}$ & Rest. & $\begin{array}{l}\text { Feb. } \\
(1.0)\end{array}$ & $\begin{array}{l}\text { Oct. } \\
(1.6)\end{array}$ & $\begin{array}{l}\text { Oct. } \\
(2.7)\end{array}$ & $\begin{array}{l}\text { Aug. } \\
(4.5)\end{array}$ & - & $\begin{array}{l}\text { Aug. } \\
(6.4)\end{array}$ & - & $\begin{array}{l}\text { Jun. } \\
(8.3)\end{array}$ & - \\
\hline BELL & Béard $^{c}$ & BEAR & 730 & 60 & - & - & $\begin{array}{l}\text { Apr. } \\
(0.9)\end{array}$ & Rest. & $\begin{array}{l}\text { Feb. } \\
(1.0)\end{array}$ & $\begin{array}{l}\text { Oct. } \\
(1.6)\end{array}$ & $\begin{array}{l}\text { Oct. } \\
(2.7)\end{array}$ & $\begin{array}{l}\text { Aug. } \\
(4.5)\end{array}$ & - & $\begin{array}{l}\text { Aug. } \\
(6.4)\end{array}$ & - & $\begin{array}{l}\text { Jun. } \\
(8.3)\end{array}$ & - \\
\hline BELL & Fournier $^{c}$ & FOUR & 740 & 225 & - & - & $\begin{array}{l}\text { Apr. } \\
(0.9)\end{array}$ & Rest. & $\begin{array}{l}\text { Mar. } \\
(1.1)\end{array}$ & $\begin{array}{l}\text { Oct. } \\
(1.6)\end{array}$ & $\begin{array}{l}\text { Oct. } \\
(2.7)\end{array}$ & $\begin{array}{l}\text { Aug. } \\
(4.5)\end{array}$ & - & $\begin{array}{l}\text { Aug. } \\
(6.4)\end{array}$ & - & $\begin{array}{l}\text { Jun. } \\
(8.3)\end{array}$ & - \\
\hline BELL & Lucey $^{c}$ & LUCE & 1210 & - & - & - & $\begin{array}{l}\text { Apr. } \\
(0.9)\end{array}$ & Rest. & $\begin{array}{l}\text { Mar. } \\
(1.1)\end{array}$ & $\begin{array}{l}\text { Oct. } \\
(1.6)\end{array}$ & $\begin{array}{l}\text { Oct. } \\
(2.6)\end{array}$ & $\begin{array}{l}\text { Aug. } \\
(4.5)\end{array}$ & - & $\begin{array}{l}\text { Aug. } \\
(6.4)\end{array}$ & - & $\begin{array}{l}\text { Jun. } \\
(8.3)\end{array}$ & - \\
\hline BELL & En l'île $e^{c}$ & ENIL & 540 & - & - & - & $\begin{array}{l}\text { Jun. } \\
(0.7)\end{array}$ & Rest. & $\begin{array}{l}\text { Feb. } \\
(1.0)\end{array}$ & $\begin{array}{l}\text { Oct. } \\
(1.6)\end{array}$ & $\begin{array}{l}\text { Oct. } \\
(2.6)\end{array}$ & $\begin{array}{l}\text { Aug. } \\
(4.5)\end{array}$ & - & $\begin{array}{l}\text { Aug. } \\
(6.4)\end{array}$ & - & $\begin{array}{l}\text { Jun. } \\
(8.3)\end{array}$ & - \\
\hline BREG & Granges $^{c}$ & GRAN & 1010 & 210 & - & - & $\begin{array}{l}\text { May } \\
(1.7)\end{array}$ & - & Rest. & $\begin{array}{l}\text { Oct. } \\
(0.7)\end{array}$ & $\begin{array}{l}\text { Oct. } \\
(1.7)\end{array}$ & $\begin{array}{l}\text { Aug. } \\
(3.6)\end{array}$ & - & $\begin{array}{l}\text { Aug. } \\
(5.5)\end{array}$ & - & $\begin{array}{l}\text { Jun. } \\
(7.4)\end{array}$ & - \\
\hline BREG & Vachon $^{c}$ & $\mathrm{VACH}$ & 850 & - & - & - & $\begin{array}{l}\text { May } \\
(1.7)\end{array}$ & - & Rest. & $\begin{array}{l}\text { Oct. } \\
(0.7)\end{array}$ & $\begin{array}{l}\text { Nov. } \\
(1.8)\end{array}$ & - & $\begin{array}{l}\text { Apr. } \\
(4.2)\end{array}$ & $\begin{array}{l}\text { Aug. } \\
(5.5)\end{array}$ & - & - & $\begin{array}{l}\text { Oct. } \\
(8.7)\end{array}$ \\
\hline BREG & Cerisiers $^{c}$ & CERI $^{\mathrm{e}}$ & 920 & 3 & - & - & $\begin{array}{l}\text { Apr. } \\
(1.8)\end{array}$ & - & Rest. & $\begin{array}{l}\text { Oct. } \\
(0.7)\end{array}$ & $\begin{array}{l}\text { Oct. } \\
(1.7)\end{array}$ & $\begin{array}{l}\text { Aug. } \\
(3.6)\end{array}$ & - & $\begin{array}{l}\text { Aug. } \\
(5.5)\end{array}$ & - & $\begin{array}{l}\text { Jun. } \\
(7.4)\end{array}$ & - \\
\hline BREG & Mathan $^{c}$ & MATH & 1715 & - & - & - & $\begin{array}{l}\text { Apr. } \\
(1.8)\end{array}$ & - & Rest. & $\begin{array}{l}\text { Oct. } \\
(0.7)\end{array}$ & $\begin{array}{l}\text { Oct. } \\
(1.8)\end{array}$ & - & $\begin{array}{l}\text { Apr. } \\
(4.2)\end{array}$ & $\underset{(5.5)}{\text { Aug. }}$ & - & - & $\begin{array}{l}\text { Oct. } \\
(8.7)\end{array}$ \\
\hline BREG & Molottes $^{c}$ & MOLO & 250 & 1220 & - & - & $\begin{array}{l}\text { Apr. } \\
(1.8)\end{array}$ & - & Rest. & $\begin{array}{l}\text { Oct. } \\
(0.7)\end{array}$ & $\begin{array}{l}\text { Nov. } \\
\text { (1.8) }\end{array}$ & & $\begin{array}{l}\text { Mar. } \\
(4.1)\end{array}$ & $\underset{(5.5)}{\text { Aug. }}$ & - & - & $\begin{array}{l}\text { Oct. } \\
(8.7)\end{array}$ \\
\hline BREG & Ponton ${ }^{\mathrm{d}}$ & PONT & 190 & 910 & - & - & $\begin{array}{l}\text { Jun. } \\
(1.6)\end{array}$ & - & Rest. & $\begin{array}{l}\text { Oct. } \\
(0.7)\end{array}$ & $\begin{array}{l}\text { Nov. } \\
(1.8)\end{array}$ & & $\begin{array}{l}\text { Mar. } \\
(4.1)\end{array}$ & $\begin{array}{l}\text { Aug. } \\
(5.5)\end{array}$ & - & $\begin{array}{l}\text { Oct. } \\
\text { (7.7) }\end{array}$ & - \\
\hline PBE & Ciselande $^{c}$ & CISE & 1090 & - & Rest. & $\begin{array}{l}\text { Aug. } \\
(4.2)\end{array}$ & - & - & - & - & $\begin{array}{l}\text { Oct. } \\
(8.4)\end{array}$ & $\begin{array}{l}\text { Sep. } \\
(10.3)\end{array}$ & - & $\begin{array}{l}\text { Jul. } \\
(12.1)\end{array}$ & - & - & $\begin{array}{l}\text { Oct. } \\
(15.4)\end{array}$ \\
\hline PBE & Jaricot $^{c}$ & JARI & 760 & 670 & Rest. & $\begin{array}{l}\text { Jul. } \\
(4.1)\end{array}$ & - & - & - & - & $\begin{array}{l}\text { Oct. } \\
(8.4)\end{array}$ & $\begin{array}{l}\text { Sep. } \\
(10.3)\end{array}$ & - & $\begin{array}{l}\text { Jul. } \\
(12.1)\end{array}$ & - & - & $\begin{array}{l}\text { Oct. } \\
(15.4)\end{array}$ \\
\hline
\end{tabular}

${ }^{\text {a }}$ Reach code signification: $\mathrm{CHAU}=$ Chautagne; $\mathrm{BELL}=$ Belley; $\mathrm{BREG}=$ Brégnier-Cordon; PBE= Pierre-Bénite.

${ }^{\mathrm{b}}$ Two surveys were performed in restored side channels of the bypassed reaches of CHAU and BELL in 2006: in spring (noted '2006a') and in autumn (noted '2006b').

${ }^{\mathrm{c}}$ Channels located in bypassed reaches.

${ }^{\mathrm{d}}$ Channels not located in bypassed reaches. Water level fluctuations in BROT match the total discharge of the Rhône (i.e., bypassed reach discharge plus artificial channel discharge), but this channel is located at the downstream end of the bypassed reach of CHAU (cf. Fig. 1C).

${ }^{\mathrm{e}}$ The restoration of CERI implied minor improvement. The channel was dredged locally ( $\mathrm{ca} .100 \mathrm{~m}$ of the $920 \mathrm{~m}$ of the side channel). Therefore, for most of our analysis we split the data into three groups: the whole channel (coded hereafter 'CERI '), the restored subsection (coded hereafter 'CERI_Rest'), and the unrestored subsection (coded

212 split the data into three 
2.3. Characterizing post-restoration spatial patterns of fine sediment deposition and their changes through time

\subsubsection{Overview of dynamics and patterns: accumulation vs. scouring processes}

As a first step, we explored the general behaviour of restored channels in terms of the longitudinal patterns and dynamics (i.e., accumulation $v s$. scouring processes) of fine sediment deposition in space and in time. We monitored fine sediment coverage (i.e., the proportion of the monitored channel length covered by fine sediments — as estimated from measuring points performed every $10 \mathrm{~m}$ along the centerline - fine sediment thickness, and fine sediment deposition rate. After restoration, we used the initial coarse surface as reference to compute long-term annual fine sediment deposition rates $\left(F S R, \mathrm{~cm} \cdot \mathrm{y}^{-1}\right)$ with reference to time since restoration (T0). For a given survey (at $\left.T+x\right)$ and a given measured point location along a side channel, we computed rates using the following ratio:

$F S R=\frac{\text { Local fine sediment thickness }(T+x)}{\text { Time since restoration completion }(T 0)}$

\subsubsection{Comparing pre- and post-restoration data}

We compared pre- and post-restoration measurements of fine sediment thickness and deposition rates in order to assess the effects of restoration. We used as the denominator in Eq. (1) the time span between the date of surveys and the estimated date of isolation of the upstream end of channels. We assumed that the date of establishment of an alluvial plug or a dyke is a good approximation for the initial date of fine sediment deposition. To determine this date, we used 1:10,000 georeferenced historical maps dating from ca. 1860 (see e.g., Bravard, 2010) and aerial photographs taken since 1930 at 5- to 12-year intervals or the available literature (Bravard, 1987; Gaydou, 2013).

\subsubsection{Typology of time-averaged post-restoration sedimentary conditions}

To summarize fine sediment deposition patterns observed in restored channels, we implemented a between-channel Principal Components Analysis (PCA), using the 'ADE4' package in R software (Chessel et al., 2004). The between-channel PCA focuses on the site effect, i.e., differences in timeaveraged conditions among channels. We also established a typology of these time-averaged conditions using a hierarchical clustering analysis performed on the first two components of the between-channel PCA, following Riquier et al. (2015). 
The PCA is based on seven environmental parameters computed for each channel and each survey: (i) the channel-averaged fine sediment thickness $(\mathrm{cm})$; (ii) the fine sediment coverage, as defined in section 2.3.1 (\%); (iii) the normalized number of fine deposit patches, defined as the number of contiguous patches of fine sediment (i.e., derived from our measures every $10 \mathrm{~m}$ along the centerline of channels) divided by the total monitored length; (iv) the ratio between the average length of contiguous patches of fine sediment deposits and the total monitored length; (v) the proportion of the total fine sediment thickness measured at $50 \%$ of the overall monitoring length (\%); (vi) the proportion of the total fine sediment thickness measured between $25 \%$ and $75 \%$ of the overall monitoring length (\%); and (vii) the slope of these linear regressions between the thickness of point deposits and the longitudinal distance (from upstream to downstream) as a proxy of the overall longitudinal trend in fine sediment thickness (i.e., no significant longitudinal gradient, increase or decrease in fine sediment thickness). The first four variables account for the ability of channels to accumulate or scour fine deposits in the vertical dimension (i) and their overall ability to accumulate or scour fine deposits along their length (longitudinal dimension, ii to iv). The last three metrics summarize the longitudinal structure of fine deposits ( $v$ to vii).

\subsection{Modeling and assessing fine sediment accumulation temporal trajectories}

\subsubsection{Modeling fine sediment deposition through time}

To explore the evolution of channel-averaged fine sediment accumulation after restoration, we tested two alternative parametric equations following a power or an exponential shape:

$\overline{F S T}=\alpha T^{(1-\beta)}$

$\overline{F S T}=\alpha(1-\exp [-\beta T])$

where $\overline{F S T}$ is the channel-averaged fine sediment thickness, and $T$ is the time since restoration $(T 0)$. In both models, $\alpha$ is a shape parameter depicting the propensity of channels to accumulate fine deposits; $\beta$ is a rate parameter representing the potential decrease of fine sediment deposition according to $T$, following either a power (Eq. 2) or an exponential decay (Eq. 3). Equations were constrained so that we always get a null value of $\overline{F S T}$ at $T 0$. 
The models were designed to mimic the rate of fine sediment deposition until potential complete terrestrialization of channels. Therefore, the power formulation (Eq. 3) was not implying an (physically unrealistic) infinite deposition, but a continuous deposition until obligate terrestrialization. By contrast, using the exponential form (Eq. 2) did not imply an obligate terrestrialization because it assumed convergence to an equilibrium thickness; this model would predict terrestrialization only if the modeled sediment thickness reaches the initial water depth of the channel. In reality, sediment deposition rates are irregular (linked to floods), and these alternative continuous parametric forms can be viewed as alternative smoothers of the actual sedimentation dynamics.

We used two different approaches to estimate $\alpha$ and $\beta$. The estimates of regression coefficients for each equation were either based on (i) a conventional approach (where a sedimentation curve for each channel is fitted independently), or on (ii) nonlinear mixed-effects models. In the first case (i), model parameters were estimated per channel and per equation form (i.e., power vs. exponential function) using the 'nlminb' function of the package 'Stats' of R software (R Core Team, 2016). In the second case (ii), we used nonlinear mixed-effects (NLME) models fitted by maximum likelihood with the 'nlme' function of the package 'nlme' of R software (R Core Team, 2016) to include fixed and random effects in the regression. For these mixed models, we considered the $\beta$ parameter (i.e., the rate parameter in Eqs. 2 and 3) as a fixed parameter shared by all channels. This fixed $\beta$ parameter depicts a general constant decay rate among channels. By contrast, the $\alpha$ parameter has a random component across channels. Therefore, $\alpha$ varies among channels around a fixed, average value.

In summary, we tested four different models (two equation forms $\times$ two modeling approaches). We evaluated the goodness-of-fit of these models by comparing their root mean square error (RMSE). We then used all or part of these four models according to research questions addressed.

\subsubsection{Trend analysis: exploring the effect of time since restoration}

291 Because of the limited number of surveys, we tested the statistical significance of $\overline{F S T}$ changes

292 through time (null hypothesis $\mathrm{H}_{0}$ : T has no effect on $\overline{F S T}$ ) using permutation tests associated with Eqs.

293 (2) and (3). For these tests, $\overline{F S T}$ values were randomly permutated among surveys $(N=10,000)$, 
parametric models were re-fitted (using the conventional approach), and their RMSE estimated. The RMSE of the observed data was then compared to those acquired by permutations to obtain P-values.

\subsection{Modeling fine sediment deposition according to the flooding regime of restored side channels}

The flooding regime of restored channels was described by three environmental variables: (i) frequency and (ii) magnitude (in terms of maximum generated total boundary shear stress) of upstream overflow events, and (iii) maximum intensity of backflow events. These metrics were derived from water-level data acquired with autonomous pressure sensors (Diver, Di240, and Di501; Schlumberger water services, Delft, the Netherlands) installed in the upstream part of the permanent water body of backwater channels (1-h time step) and stage-discharge relationships for the main channel near the ends of all channels (Fig. 4). (i) The annual upstream overflow frequency (i.e., the frequency of lotic functioning; hereafter upstream overflow frequency, noted $\bar{f}_{Q b}$ ) refers to the number of days per year during which the main channel overflowed the upstream plug of side channels (e.g., side channels connected permanently at both ends have an average flow frequency of $\left.365.25 \mathrm{~d}^{-1} \mathrm{y}^{-1}\right)$. See Riquier et al. (2015) for details regarding the quantification of upstream overflow discharge. (ii) The magnitude of upstream overflow events was estimated from the hourly maximum (over the post-restoration period) of the spatially averaged total boundary shear stress recorded by each side channel (noted $\bar{\tau}_{\text {max }}$; hereafter maximum shear stress). Maximum shear stress values usually match the maximum hourly discharge. Note that for backwater channels, we used average water-surface slopes derived from water levels estimated at our pressure sensors and in the main channel at the downstream end of the backwater channels (Fig. 4A). For side channels permanently connected with the main channel at both ends, average water-surface slopes were estimated by multiplying the slope of the main channel by the ratio of main channel centerline length to side channel centerline length. Further details regarding the computation of this metric can be found in Riquier et al. (2015). (iii) Pressure sensors being located in the upstream part of the permanent water bodies, we estimated their respective maximum potential intensity of backflow events along their total length (noted $\overline{B f}_{\text {max }}$, hereafter 

overflow.

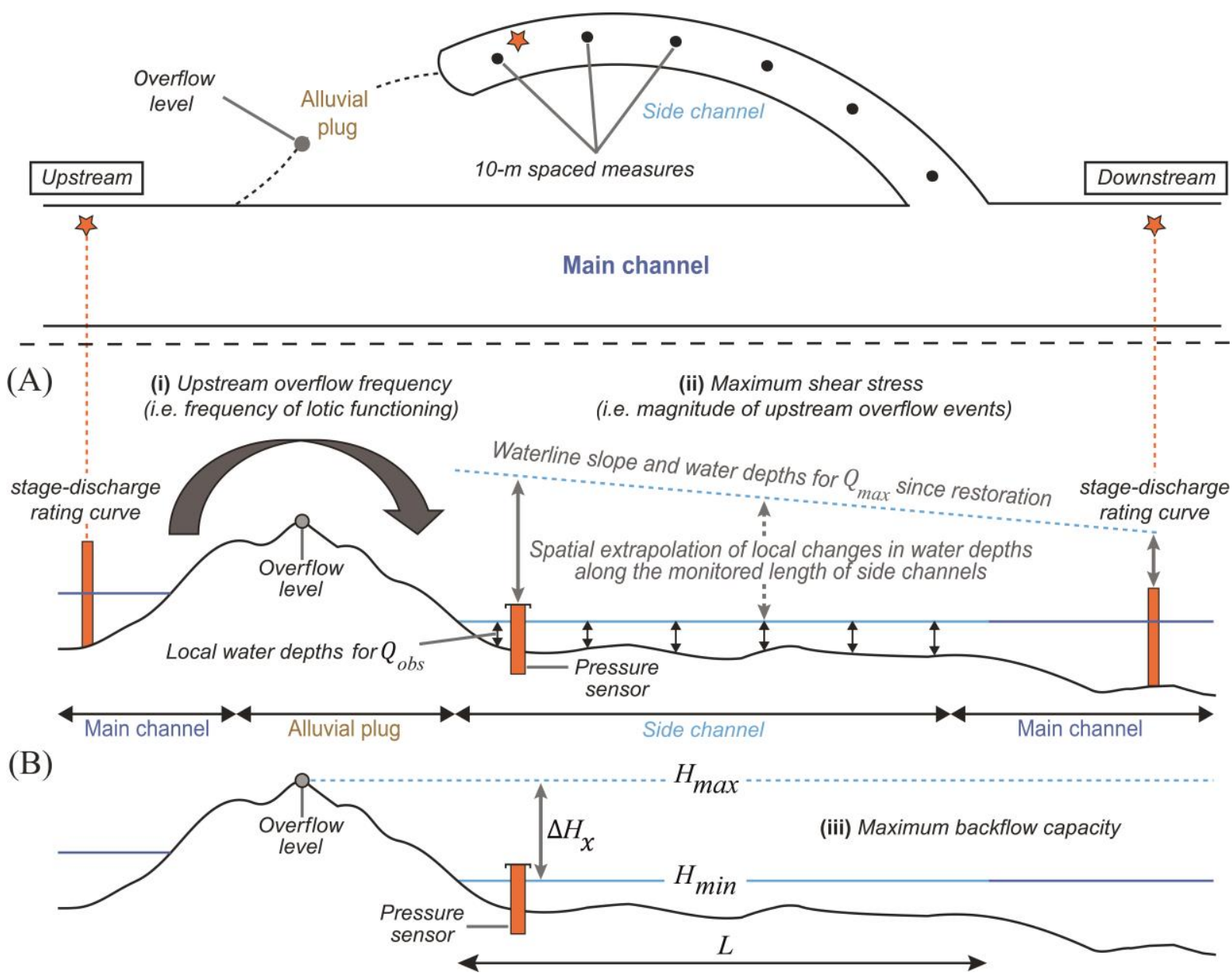

Fig. 4. General principles of the method used to quantify the flooding regime of side channels (modified from Riquier et al., 2015): (A) upstream overflow frequency and maximum shear stress and (B) maximum backflow capacity.

This metric is estimated as follows:

$\overline{B f}_{\max }=\frac{\Delta H_{x}}{L}$

where $\Delta H_{x}$ is the estimated local change in water level between $H_{\max }$, the water level at our pressure sensors immediately before the upstream alluvial plug overflows, and $H_{\min }$, the water level at our pressure sensors for the maximum value of the legal minimum flow, which is modulated throughout a year. For channels not located in bypassed reaches, we replace $H_{\min }$ by $\bar{H}$, the water level at the pressure sensor corresponding to the average discharge of the related reach of the river. The $\Delta H_{x}$ was divided by $L$, the length of the permanent water body of channels, to normalize for length. This ratio provided us a spatially averaged slope $\left(\mathrm{m}^{\mathrm{m}} \mathrm{m}^{-1}\right)$ used as an indicator of the overall capacity of side 
channels magnitude to trap fine sediment during backflow events. Values of $\overline{B f}_{\text {max }}$ for active secondary channels permanently connected at both ends are equal to 0 , whatever their length.

We then used simple and multiple regression analysis to test relationships between these three metrics depicting the flooding regime of channels with values of the shape parameter $\alpha$ previously computed for each channel (Eqs. 2 and 3). We chose $\alpha$ values derived from the more accurate of the two NLME models (i.e., using either $\alpha$ values derived from the power form or from the exponential form) through a comparison of their respective RMSE values. Working with the $\alpha$ parameter derived from NLME models ensures that we work on a similar basis for all channels because the rate parameter $\beta$ is fixed.

\subsection{Estimating the potential persistence of restored side channels as aquatic habitats}

To assess the potential persistence of restored channels as aquatic habitats, we assumed that the channel is essentially terrestrialized once the average sedimentation thickness reaches the average channel depth between water surface and gravel layer observed immediately after restoration (hereafter, initial channel depth).

To estimate this initial channel depth, we used water depths measured during the first complete bathymetric surveys. Because these measures were undertaken during varying flow conditions, we corrected them to a similar reference water stage/discharge among channels. The chosen reference value was the maximum value (across months) of the minimal flow guaranteed in the bypassed reach. For channels not located in bypassed reaches (i.e., located along total Rhône sections; see Table 1), we used the water stage related to the average discharge of the corresponding reach of the river as the reference.

In practice, for the water depth correction, we estimated local changes in water stages between the reference water stage/discharge and the stage/discharge observed during field measurements. For active secondary channels, we used the method developed in Riquier et al. (2015) that relies on spatial extrapolation of stage-discharge rating curves established in the main channel at both ends of each active side channel along their length (see their Eq. 3 and Fig. 2 for details). For backwater channels, we assumed that the slope of the water level during measurements was null (permanent flow), so that 
362 we directly corrected water depths from observations of water stages at our pressure sensors. Finally, we summed the average corrected water depth and the average fine sediment thickness measured during the corresponding survey to get an initial average channel depth for each channel. with the time since restoration (see section 2.4.1). Here, we assumed that terrestrialization processes would be only driven by fine sediment accumulation. Our four models of sedimentation rates provided four longevity estimates. For the power parametric models, we considered that terrestrialization occurred when the initial channel depth was reached. Therefore, these models were realistic although the power formulation would allow an infinite deposition. The exponential form of our models (Eq. 3) is the only one for which terrestrialization is not obligate and for which side channels can reach equilibrium with persistent aquatic habitat. The two forms of the mixed-effects models allowed us to provide additional potential scenarios of evolution of fine sediment infilling using a general decay rate determined at the population-level (see section 2.4.1), since it remains large uncertainties about the decline or not of fine sedimentation through time over the long term. Overall, our four different estimates were used to appreciate the uncertainty of channel longevity estimations.

\section{Results}

\subsection{Accumulation vs. scouring processes in space and time}

\subsubsection{Raw results}

Fine sediment deposition is highly variable in space and time between- and within-channels (Table 2; Figs. 5 to 8). With the exception of VACH, all channels exhibited fine sediment deposits at least for one survey.

Some channels showed thin patches of fine deposits, producing a typical stair-step longitudinal evolution of deposits (e.g., FOUR; Figs. 7 and 8). These channels contrast with those that exhibited longer segments with fine deposits and where fine sediments tended to be homogenously distributed along the entire channel length (e.g., MOLO), or preferentially located in the upstream (e.g., BROT) or the downstream parts of the channels (e.g., JARI). Others showed a combination of very localized 
patches of fine deposits juxtaposed with longer segments with more or less important and extended deposits (e.g., CERI or GRAN). These longitudinal patterns of fine deposits can be relatively stable through time (e.g., MOLO) or very dynamic (e.g., LUCE). In some channels, we observed that the longitudinal organization of fine deposits gradually becomes more homogenous (especially in BROT and to a lesser extent in MOIR and BEAR). In terms of fine sediment coverage changes, the most drastic increase in fine sediment coverage observed between two surveys was in LUCE between August 2009 and August $2011(+36 \%)$.

Regarding fine sediment thickness, some channels remained gravel-bedded most of the time (FOUR, ENIL, VACH, and MATH). On the other hand, some channel beds were quickly totally covered by fine sediments after restoration and clearly accumulated fine deposits (MALO, MOLO, or PONT). The other channels exhibited more or less complex trajectories between these two extremes. The channel-averaged fine sediment thickness varied between $0 \mathrm{~cm}$ (e.g., ENIL in June 2013, $T+8.3$ years after restoration) and $94.2 \mathrm{~cm}$ (PONT in October 2013, $T+7.7$; Table 2). Locally fine sediment depth above the reference gravel layer observed right after restoration reached a maximum of 187.6 $\mathrm{cm}$ (observed in BEAR during the survey of June 2013 at $T+8.3$ ).

When expressed in term of channel-averaged fine sediment deposition rate, values ranged from 0 cm. $\mathrm{y}^{-1}$ (e.g., MATH in October 2014, $T+8.7$ ) to $40.3 \mathrm{~cm} . \mathrm{y}^{-1}$ (PONT in October 2006, $T+0.7$ ). The maximum fine sediment deposition rate was observed in MOLO during the survey of October 2007, with a local rate of $90.3 \mathrm{~cm} \cdot \mathrm{y}^{-1}$. The greatest accumulation of fine deposits between two surveys was observed in PONT between August 2011 and October 2013, with an average $+31.4 \mathrm{~cm}$, equivalent to an average intersurvey rate of $14.4 \mathrm{~cm} \cdot \mathrm{y}^{-1}$ (rate computed from one survey to the next).

All channels exhibited fine sediment scouring at least during one survey (Table 2), with the exception of MOLO. Curves of cumulative deposition also allowed us to localize, for intersurveys with a predominance of erosion processes over sedimentation, the sections that were more sensitive to scouring processes. For example, for BEAR these graphs identified the section between $c a$. 300 to 700 $m$ downstream from the upstream reference point as having been very sensitive to erosion during the October 2006-October 2007 time period (compare Figs. 5 and 8 for BEAR for this period). We observed scouring in most of the channels located in reaches of the upper Rhône (i.e., Chautagne, 
417 Belley, and Brégnier-Cordon reaches) during the October 2006-October 2007 intersurvey time period.

418 Only ENIL, VACH, MOLO, and the restored subsection of CERI did not show erosive processes

419 during this period. This pseudo-synchrony of scouring events was also observed for the two side

420 channels of the PBN bypassed reach but during the 2007-2009 intersurvey period. Other time periods

421 were characterized by a predominance of scouring processes over sedimentation in some channels,

422 notably during the 2011-2013 intersurvey period. In terms of fine sediment coverage dynamics, the

423 largest decrease in fine sediment coverage between two surveys was observed in BEAR between

424 October 2006 and October 2007 (-49.2\%). The greatest erosion of fine deposits between two surveys

425 was observed in LUIS between August 2011 and June 2013, with an average $-7.2 \mathrm{~cm}$. 
Table 2

Some post-restoration characteristics of side channels in terms of fine sediment dynamics; shaded cells depict intersurvey time periods including scouring of fine deposits (i.e., a decrease in average fine sediment thickness or fine sediment coverage from one survey to the next) (see Table 1 for channel codes)

\begin{tabular}{|c|c|c|c|c|c|c|c|c|c|c|c|c|c|c|c|c|c|c|c|}
\hline & \multirow{2}{*}{$\begin{array}{l}\text { Year of } \\
\text { survey }\end{array}$} & \multicolumn{18}{|c|}{ Side channels } \\
\hline & & MALO & BROT & LUIS & MOIR & BEAR & FOUR & LUCE & ENIL & GRAN & VACH & $\begin{array}{l}\text { CERI } \\
\text { 'All' }\end{array}$ & $\begin{array}{l}\text { CERI } \\
\text { 'Unrest' }\end{array}$ & $\begin{array}{l}\text { CERI } \\
\text { 'Rest' }\end{array}$ & MATH & MOLO & PONT & CISE & JARI \\
\hline \multirow{10}{*}{$\begin{array}{l}\text { Fine sediment coverage } \\
\qquad(F S C, \%)\end{array}$} & 2003 & - & - & - & - & - & - & - & - & - & & - & - & - & - & - & - & 42.0 & 82.0 \\
\hline & $2006 \mathrm{a}^{\mathrm{a}}$ & 100.0 & 47.7 & 69.6 & 75.0 & 39.7 & 10.8 & 5.8 & 11.8 & - & - & - & - & - & - & - & - & - & - \\
\hline & $2006 b^{a}$ & 100.0 & 69.2 & 43.5 & 83.8 & 74.6 & 3.8 & 23.1 & 0.0 & 10.9 & 0.0 & 23.9 & 24.4 & 20.0 & 5.0 & 100.0 & 100.0 & - & - \\
\hline & 2007 & 100.0 & 61.5 & 39.1 & 63.2 & 25.4 & 0.0 & 6.6 & 0.0 & 6.9 & 0.0 & 20.7 & 15.9 & 60.0 & 0.0 & 100.0 & 100.0 & 74.1 & 93.5 \\
\hline & 2009 & 97.2 & 83.1 & 50.0 & 91.2 & 69.8 & 0.0 & 8.3 & 0.0 & 30.7 & - & - & 35.4 & 100.0 & - & - & - & 46.3 & 68.4 \\
\hline & 2010 & - & - & - & - & - & - & - & - & - & 0.0 & 42.4 & - & - & 1.9 & 100.0 & 100.0 & - & - \\
\hline & 2011 & 94.4 & 98.5 & 50.0 & 95.6 & 71.4 & 0.0 & 44.6 & 25.9 & 41.6 & 0.0 & 58.7 & 53.7 & 100.0 & 0.0 & 100.0 & 100.0 & 48.1 & 89.5 \\
\hline & 2012 & 97.2 & - & - & - & - & - & - & - & - & - & - & - & - & - & - & 100.0 & - & - \\
\hline & 2013 & 97.2 & 95.4 & 28.3 & 88.2 & 88.9 & 13.9 & 38.0 & 0.0 & 36.6 & - & 56.5 & 51.2 & 100.0 & - & - & - & - & - \\
\hline & 2014 & - & - & - & - & - & - & & - & - & 0.0 & - & - & - & 0.0 & 100.0 & - & 55.6 & 90.8 \\
\hline \multirow{10}{*}{$\begin{array}{c}\text { Channel-averaged fine } \\
\text { sediment thickness } \\
(\overline{F S T}, \mathrm{~cm})\end{array}$} & 2003 & - & - & - & - & - & - & - & - & - & - & - & - & - & - & - & - & 0.7 & 16.7 \\
\hline & $2006 a^{a}$ & 25.5 & 7.7 & 13.6 & 7.4 & 3.7 & 1.0 & 0.5 & 1.3 & - & - & - & - & - & - & - & - & - & - \\
\hline & $2006 b^{a}$ & 37.6 & 13.0 & 7.6 & 11.0 & 6.6 & 0.3 & 2.5 & 0.0 & 1.9 & 0.0 & 7.5 & 7.6 & 4.6 & 0.9 & 28.5 & 29.5 & - & - \\
\hline & 2007 & 32.9 & 20.7 & 7.2 & 8.1 & 3.3 & 0.0 & 0.5 & 0.0 & 0.9 & 0.0 & 4.7 & 3.1 & 16.8 & 0.0 & 37.6 & 26.7 & 11.0 & 18.9 \\
\hline & 2009 & 46.7 & 22.5 & 12.1 & 12.3 & 9.3 & 0.0 & 0.6 & 0.0 & 4.7 & - & 11.7 & 8.1 & 43.0 & - & - & - & 10.0 & 13.0 \\
\hline & 2010 & - & - & - & - & - & - & - & - & - & 0.0 & - & - & - & 0.5 & 59.4 & 52.0 & - & - \\
\hline & 2011 & 54.0 & 35.5 & 8.6 & 17.4 & 14.3 & 0.0 & 7.0 & 2.5 & 7.4 & 0.0 & 21.6 & 17.0 & 66.0 & 0.0 & 69.3 & 62.8 & 11.3 & 23.4 \\
\hline & 2012 & 58.2 & - & - & - & - & - & - & - & - & - & - & - & - & - & - & - & - & - \\
\hline & 2013 & 59.9 & 43.1 & 1.4 & 29.6 & 21.4 & 0.4 & 6.7 & 0.0 & 7.2 & - & 25.2 & 21.3 & 64.2 & - & - & 94.2 & - & - \\
\hline & 2014 & - & - & - & - & - & - & - & - & - & 0.0 & - & - & - & 0.0 & 89.1 & - & 11.7 & 27.3 \\
\hline \multirow{10}{*}{$\begin{array}{l}\text { Channel-averaged fine } \\
\text { sediment deposition rate } \\
\left(\overline{F S R}, \mathrm{~cm}^{-1} \mathrm{y}^{-1} \text { computed }\right. \\
\text { in reference to restoration } \\
\text { completion, see Eq. } 1)\end{array}$} & 2003 & - & - & - & - & - & - & - & - & - & - & - & - & - & - & - & - & 0.2 & 4.1 \\
\hline & $2006 \mathrm{a}^{\mathrm{a}}$ & 11.9 & 3.6 & 14.4 & 7.6 & 3.8 & 1.0 & 0.4 & 1.3 & - & - & - & - & - & - & - & - & - & - \\
\hline & $2006 b^{a}$ & 13.9 & 4.8 & 4.7 & 6.7 & 4.0 & 0.2 & 1.5 & 0.0 & 2.7 & 0.0 & 0.8 & 0.1 & 6.4 & 1.2 & 38.9 & 40.3 & - & - \\
\hline & 2007 & 8.8 & 5.5 & 2.7 & 3.1 & 1.2 & 0.0 & 0.2 & 0.0 & 0.5 & 0.0 & 1.0 & 0.0 & 8.9 & 0.0 & 21.0 & 15.0 & 1.3 & 2.3 \\
\hline & 2009 & 8.4 & 4.0 & 2.7 & 2.8 & 2.1 & 0.0 & 0.1 & 0.0 & 1.3 & - & 1.3 & 0.1 & 11.4 & - & - & - & 1.0 & 1.3 \\
\hline & 2010 & - & - & - & - & - & - & - & - & - & 0.0 & - & - & - & 0.1 & 14.6 & 12.8 & - & - \\
\hline & 2011 & 7.2 & 4.7 & 1.3 & 2.7 & 2.2 & 0.0 & 1.1 & 0.4 & 1.3 & 0.0 & 1.4 & 0.1 & 11.5 & 0.0 & 12.5 & 11.3 & 0.9 & 1.9 \\
\hline & 2012 & 6.8 & - & - & - & - & - & - & - & - & - & - & & - & - & - & - & - & - \\
\hline & 2013 & 6.4 & 4.6 & 0.2 & 3.6 & 2.6 & 0.0 & 0.8 & 0.0 & 1.0 & & 1.1 & $0 . .2$ & 8.3 & - & - & 12.2 & - & - \\
\hline & 2014 & - & - & - & - & - & - & - & - & - & 0.0 & - & - & - & 0.0 & 10.2 & - & 0.8 & 1.8 \\
\hline
\end{tabular}

a Spring 2006: '2006a'; autumn 2006: '2006b'. 

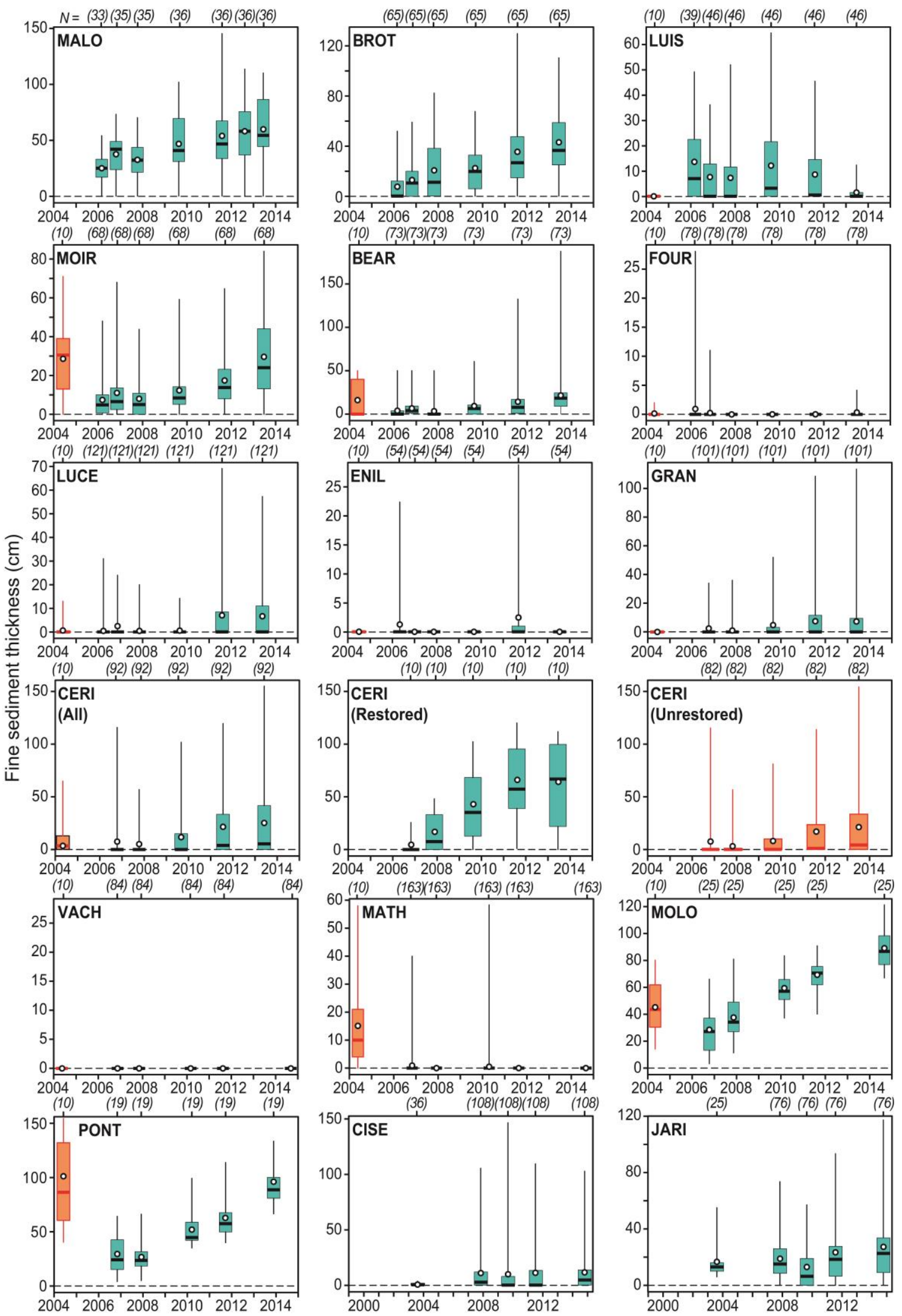

Fig. 5. Temporal evolution of the statistical distribution of measured fine sediment thickness through time. Boxes represent the 25th and 75th percentiles. Bold horizontal lines are the median, and circles depict the average. Lower and upper vertical lines denote the minimum and maximum values. Red boxes depict pre-restoration data, and blue boxes represent post-restoration data. Numbers under brackets refer to the number of local probing points performed during each survey. 

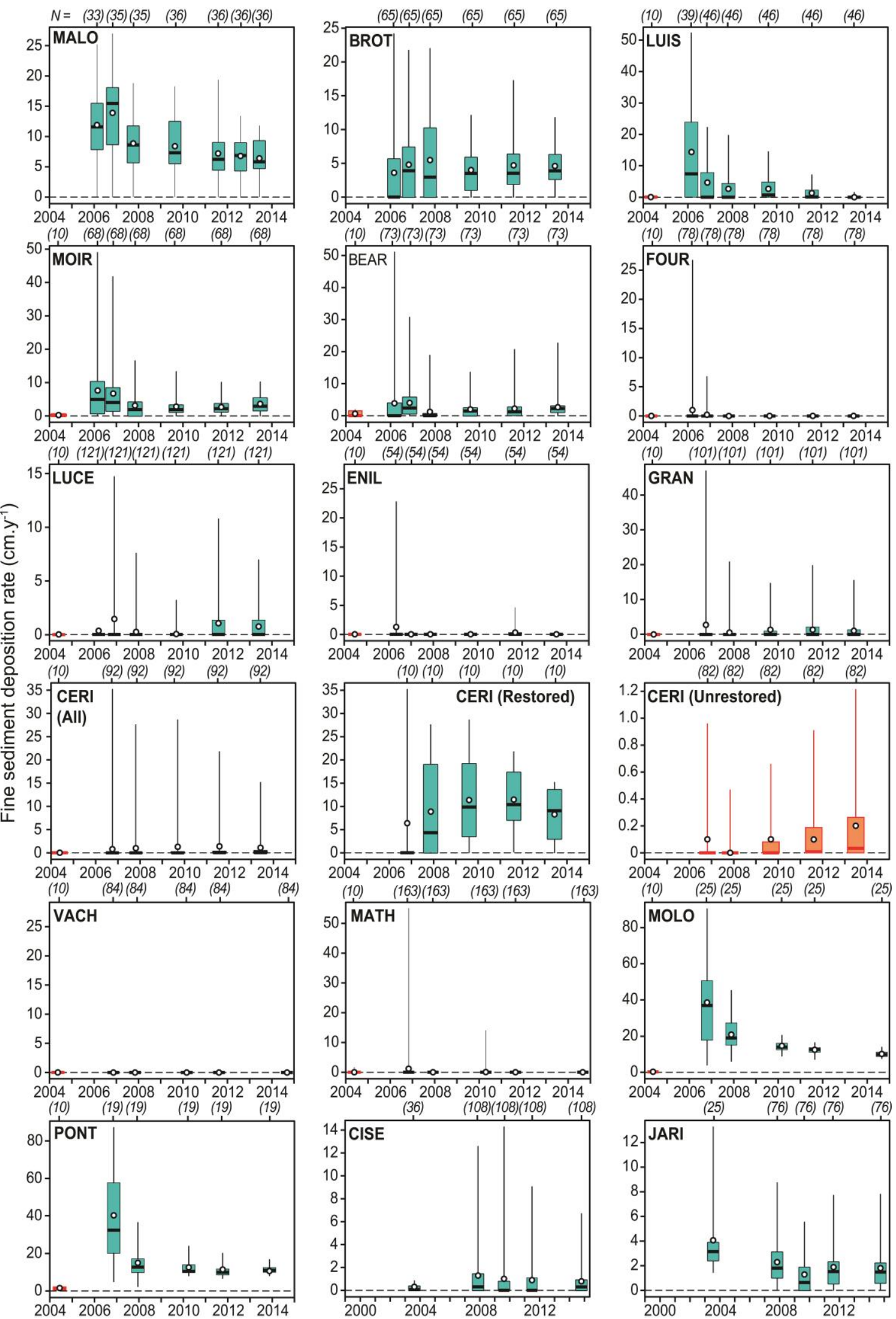

Fig. 6. Temporal evolution of the statistical distribution of annual fine sediment deposition rates computed in reference to restoration completion dates (T0, see Table 1). Boxes represent the 25th and 75th percentiles. Bold horizontal lines are the median, and circles depict the average. Lower and upper vertical lines denote the 
441 restoration data. Numbers under brackets refer to the number of local probing points performed during each 442 survey. 

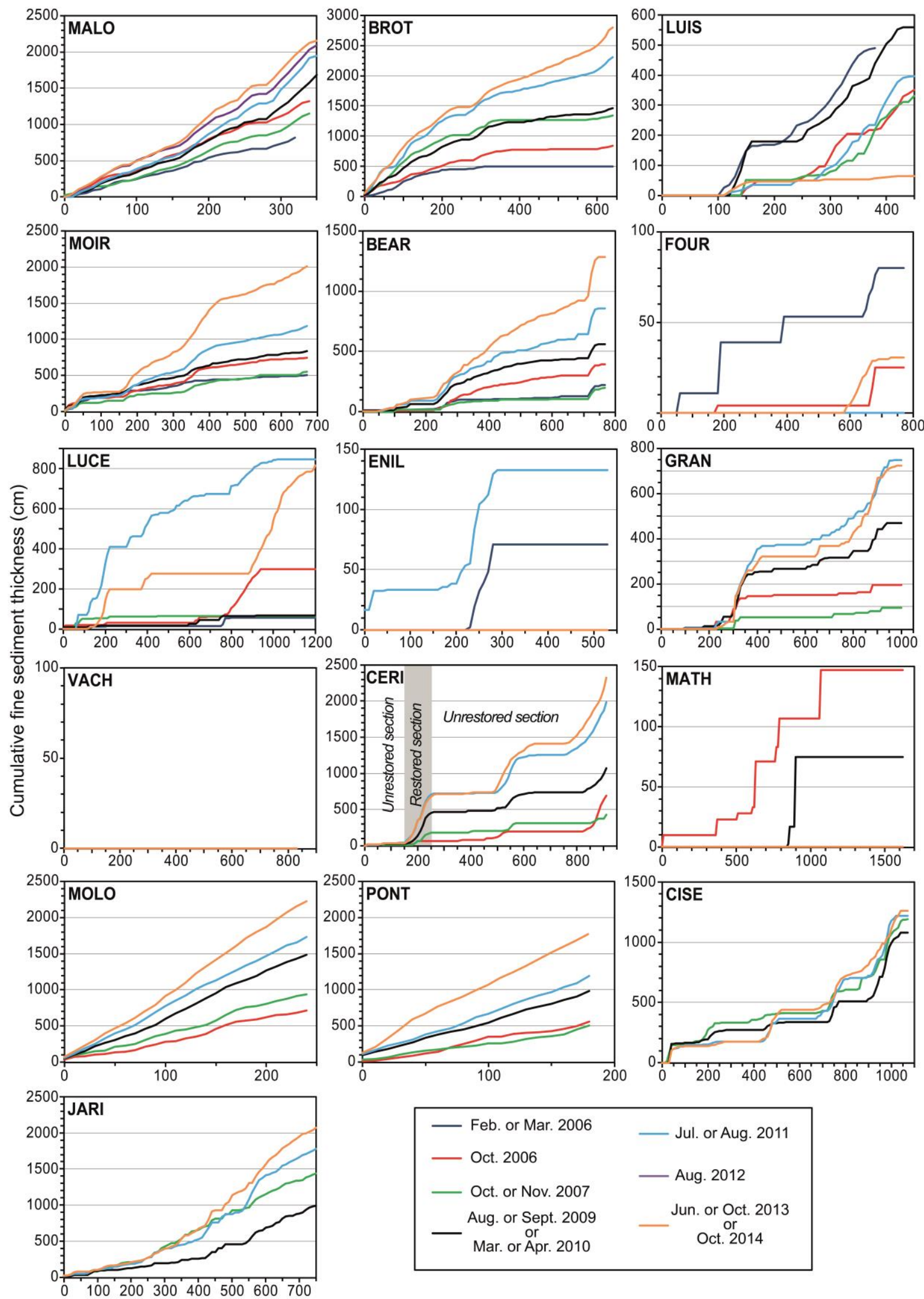

Distance from upstream along side channels median axis $(\mathrm{m})$

Fig. 7. Cumulative fine sediment thickness along each channel monitored length. See Table 1 for more 

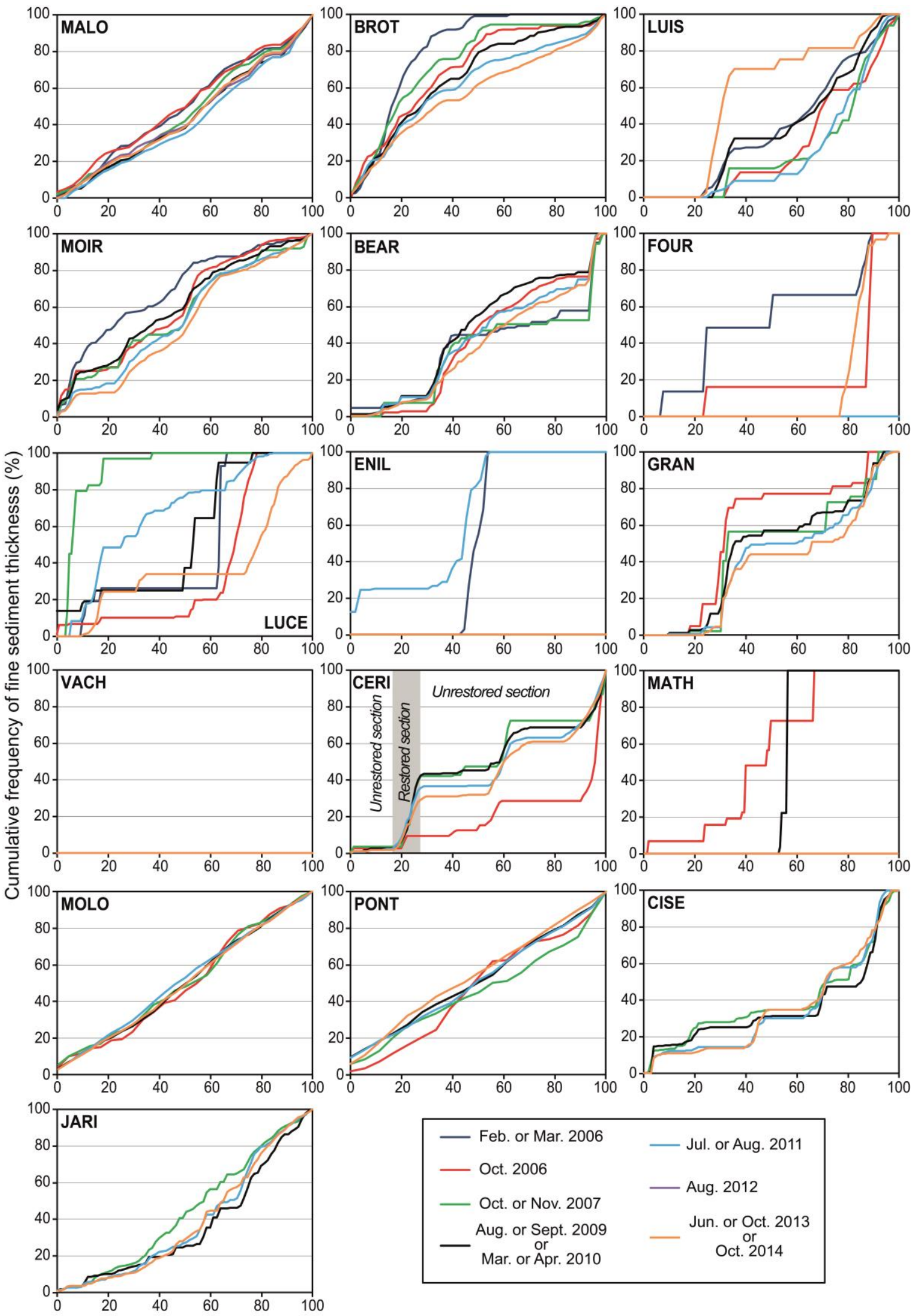

Relative length of side channels (\%)

Fig. 8. Cumulative frequency of relative fine sediment thickness measured locally along the monitored relative lengths of channels (i.e., the proportion of fine sediment thickness in relation to total fine sediment thickness measured during a given survey in a given channel). See Table 1 for more precise dates of surveys. 
453

We have scarce pre-restoration data for 12 of the 16 side channels studied here (Table 1). Most of these former braided, anastomosed, or anabranched channels had been artificially isolated from the main channel at their upstream end by submersible embankments constructed at the end of the nineteenth century. Only three had been isolated by upstream alluvial plug development (Table 3).

Fine sediment deposition rates measured before restoration (Fig. 6; Table 3) were often very low, except in a few channels (BEAR, MATH, PONT, and MOLO). Post-restoration fine deposits are often thicker than pre-restoration (Fig. 5). Channel-averaged fine sediment thickness observed before restoration (Table 3) were compared with averages measured during the last surveys of 2013 or 2014 (Table 2; i.e., from $T+7.4$ to $T+8.7$, depending on the channel considered; Table 1). The largest positive difference between post- and pre-restoration averages was found in MOLO $(+44.0 \mathrm{~cm})$. Only MATH and PONT exhibited thinner fine deposits after restoration than before (difference between averages equal to -15.1 and $-6.7 \mathrm{~cm}$ respectively).

\section{Table 3}

\section{Characterization of fine sediment deposition in side channels before restoration}

\begin{tabular}{|c|c|c|c|c|c|}
\hline $\begin{array}{l}\text { Channel } \\
\text { code }\end{array}$ & $\begin{array}{l}\text { Date of } \\
\text { upstream } \\
\text { disconnection }{ }^{a} \\
\text { (lower/upper) }\end{array}$ & $\begin{array}{l}\text { Elapsed time } \\
\text { since upstream } \\
\text { disconnection }{ }^{\mathrm{a}} \\
(\mathrm{max} . / \mathrm{mean} / \mathrm{min} .)\end{array}$ & $\begin{array}{l}\text { Type of } \\
\text { disconnection }^{\text {a }}\end{array}$ & $\begin{array}{l}\overline{F S T} \text { b } \\
\text { measured } \\
\text { at } T-x \\
(\mathrm{~cm})\end{array}$ & $\begin{array}{l}\overline{F S R}^{\mathrm{c}} \\
\text { estimates at } T-x \\
(\mathrm{~min} . / \mathrm{mean} / \mathrm{max} .) \\
\left(\mathrm{cm} \cdot \mathrm{y}^{-1}\right)\end{array}$ \\
\hline LUIS & $1874 / 1875$ & $130 / 129.5 / 129$ & low dikes & 0.0 & $0.0 / 0.0 / 0.0$ \\
\hline MOIR & $1874 / 1875$ & $130 / 129.5 / 129$ & low dikes & 28.1 & $0.2 / 0.2 / 0.2$ \\
\hline BEAR & $1973 / 1982$ & $31 / 26.5 / 22$ & alluvial plug & 16.0 & $0.5 / 0.6 / 0.7$ \\
\hline FOUR & $1880 / 1900$ & $124 / 114 / 104$ & low dikes & 0.4 & $0.0 / 0.0 / 0.0$ \\
\hline LUCE & $1880 / 1900$ & $124 / 114 / 104$ & low dikes & 1.3 & $0.0 / 0.0 / 0.0$ \\
\hline ENIL & $1880 / 1900$ & $124 / 114 / 104$ & low dikes & 0.0 & $0.0 / 0.0 / 0.0$ \\
\hline GRAN & $>1860$ & $>144$ & low dikes & 0.0 & 0.0 \\
\hline $\mathrm{VACH}$ & $1879 / 1881$ & $125 / 124 / 123$ & low dikes & 0.0 & $0.0 / 0.0 / 0.0$ \\
\hline CERI & 1885 & $120 / 119.5 / 119$ & low dikes & 11.3 & $0.1 / 0.1 / 0.1$ \\
\hline MATH & $1954 / 1971$ & $50 / 41.5 / 33$ & alluvial plug & 15.1 & $0.3 / 0.4 / 0.5$ \\
\hline MOLO & 1885 & $120 / 119.5 / 119$ & low dikes & 45.1 & $0.4 / 0.4 / 0.4$ \\
\hline PONT & $1939 / 1954$ & $65 / 57.5 / 50$ & alluvial plug & 100.9 & $1.6 / 1.8 / 2.0$ \\
\hline
\end{tabular}
restoration in 2004 (Table 1) in 12 of the 16 side channels studied in this paper. 
3.2. Typology of between-channel (time-averaged) fine sediment deposition patterns observed after restoration

Seventy-seven percent of the total inertia of our data set was attributed to the between-channel variability and $23 \%$ of the total inertia was linked to the within-channel dynamics (i.e., the effect of individual temporal trajectories of each channel).

The first two axes of the PCA (Fig. 9) explained $83 \%$ of the total between-channel variance ( $57 \%$ for F1, 26\% for F2). The first axis primarily depicts the ability of channels to store fine sediment deposits along their vertical and longitudinal dimensions. Three metrics explain about $70 \%$ of the variance supported by F1: the fine sediment coverage (FSC, 25\%; see Fig. 9 for a definition of metrics codes), the normalized length of contiguous fine patches $(N p L, 22 \%)$, and the average fine sediment thickness $(\overline{F S T}, 21 \%)$. The proportion of total fine sediment thickness measured at $50 \%$ of the overall monitored length $\left(C_{-}\right.$med, $\left.11 \%\right)$ and the proportion of total fine sediment thickness measured between 25 and $75 \%$ of the total monitored length $\left(C_{-} I Q R, 11 \%\right)$ secondarily contribute to the F1 axis. The second axis reflects the longitudinal structure of fine deposits. It is mainly structured by the normalized number of fine patches $\left(N_{-} P a t c h, 39 \%\right)$ and by the normalized length of contiguous fine patches $(N p L, 21 \%)$. The proportion of total fine sediment thickness observed at $50 \%$ of the overall monitored length $\left(C_{-}\right.$med, $\left.16 \%\right)$ and the relative proportion of total fine sediment thickness measured between 25 and $75 \%$ of the total monitored length $\left(C_{-} I Q R, 15 \%\right)$ also slightly contribute to this second axis.

We identified four time-averaged types of fine sediment deposition patterns (Figs. 9B-D). Side channels of type A are clearly different from channels of type D. Types B and C constitute two intermediate cases. They are well separated from the two other types, but they share some similarities. Channels of type A have no or few very short patches of fine deposits, so that they do not exhibit any longitudinal trend in fine sediment thickness (VACH, MATH, ENIL, and FOUR). Side channels of type B (LUCE, GRAN, and BROT) and type C (CERI, CISE, LUIS, BEAR, MOIR, and JARI) are two relatively close intermediate types. Type B channels often exhibit thinner sediment deposits and less important values of fine sediment coverage than observed in type $\mathrm{C}$ channels. Patches of fine 
500 deposits tend also to be less discontinuous and slightly shorter in type B channels than observed for

501 channels of type C. Type B channels generally have higher values of $C_{-}$med and lower values of

502 C_IQR than observed in channels of type C. Among type B channels, only BROT exhibits a

503 significant downstream decrease in deposited fine sediment thickness ( $\mathrm{P}$-value $<10^{-10}$ ) in fine

504 sediment thickness, measured between the distance from upstream and time-averaged values of local

505 fine sediment thickness. LUCE and GRAN exhibit no significant longitudinal trend. Channels of type

$506 \mathrm{C}$ have more varied longitudinal gradients in fine sediment thickness. Four of these channels have a

507 downstream increase in fine sediment thickness significant at least at the $1 \% \alpha$-level for LUIS, CERI,

508 JARI, and CISE (see Figs. 7 and 8). MOIR exhibits a significant downstream decrease in deposited

509 fine sediment thickness $(\mathrm{P}$-value $<0.03)$. BEAR exhibits no significant longitudinal trend. Side

510 channels of type D are fully covered by fine sediments and have fairly continuously distributed fine

511 deposits along their length (MOLO, PONT, and MALO). They clearly have the highest propensity to

512 store fine sediments and exhibit significant downstream growth in fine sediment thickness.

513 Downstream increase in fine sediment thickness is significant at least at the $5 \% \alpha$-level for these three

514 channels. 


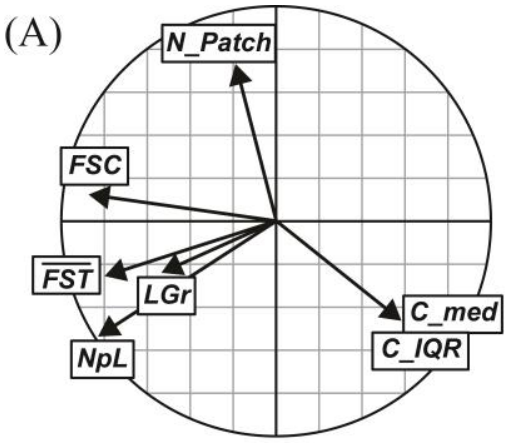

(C)

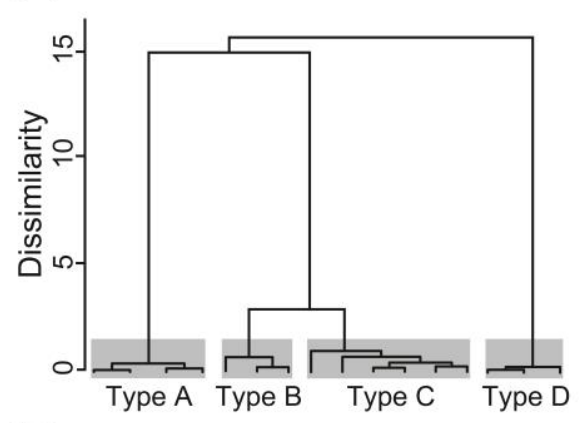

(B)

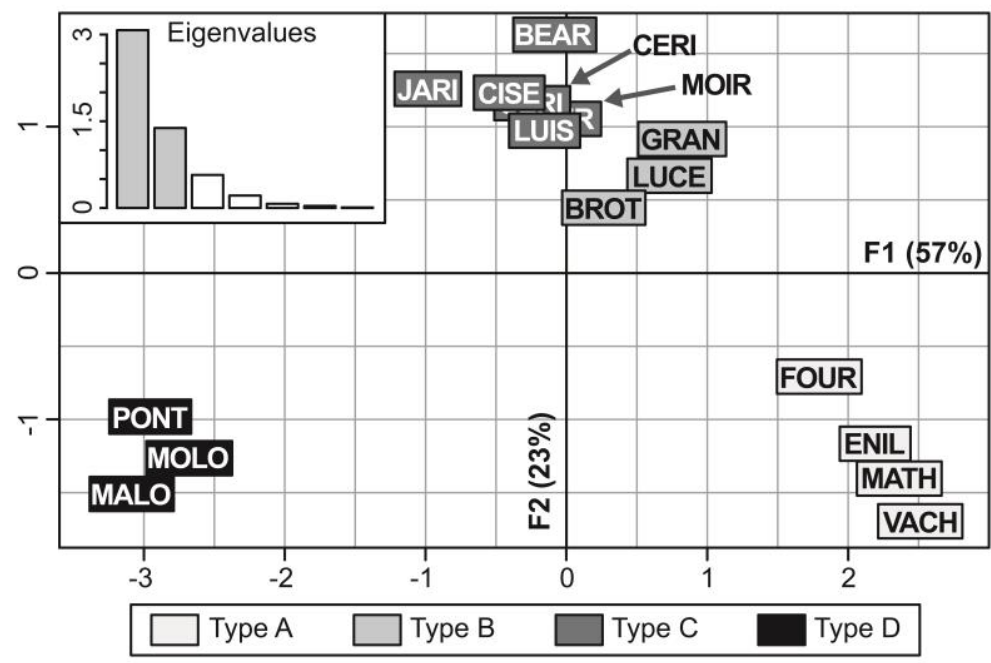

(D)
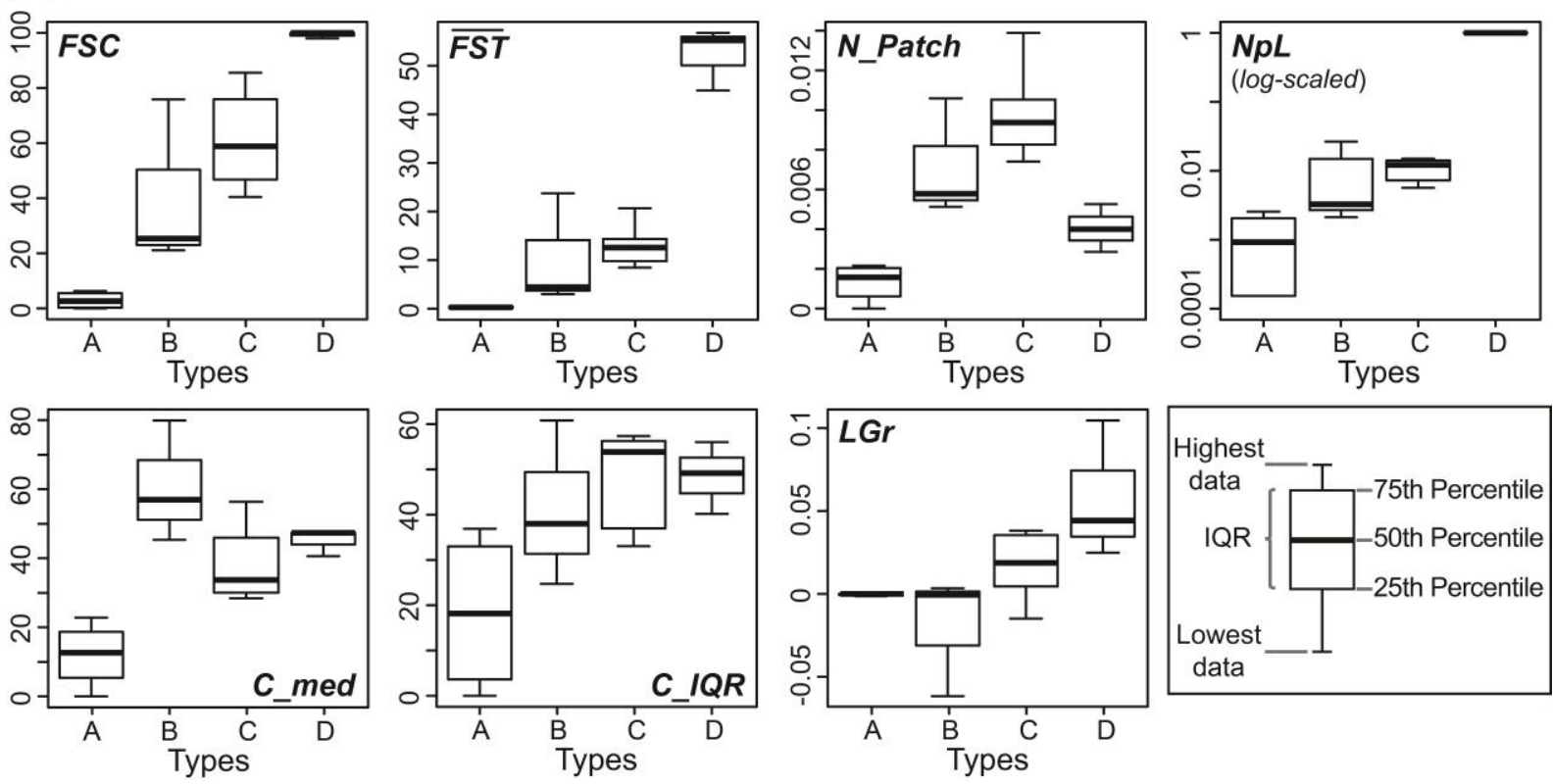

Fig. 9. Results of the between-channel principal components analysis (PCA). (A) Correlation circle of the variables describing fine-grained deposits within side channels in their post-restoration state, showing: $N p L$, the length of contiguous fine sediment patches normalized by the length of side channels; FSC, the relative length covered by fine sediments; $\overline{F S T}$, the average thickness of fine sediment deposits; $N_{-} P a t c h$, the number of contiguous patches of fine deposits normalized by the length of side channels, which is a proxy for the patchiness of fine deposits; $L G r$, an indicator of the presence/absence of a longitudinal trend in fine sediment thickness (a positive value indicates a downstream growth in fine sediment thickness). See section 2.3.3 for details regarding these metrics. (B) Factorial map F1 x F2 and eigenvalues resulting from the between-channel PCA showing four homogenous types of channel. (C) Types of channels were determined through a Hierarchical Ascendant Clustering analysis performed on channel time-averaged coordinates on the first two components of the between-channel PCA. (D) Distributions of the metrics describing fine-grained deposits within side channels by channel type (not normalized values). 
529

530

531

532

533

534

535

536

537

538

539

540

541

542

\subsection{Modeling of fine sedimentation trajectories}

\subsubsection{Efficiency of models}

The four parametric models fitted well the observed data over the range of our observations (Table 4; Fig. 10). However, consistent with their more numerous parameters, conventional models (which had two parameters for each individual channel) had lower RMSE than NLMEs (Table 4). Among conventional models, power forms better fitted the data than exponential forms $(\overline{\mathrm{RMSE}}=2.3 v \mathrm{vs} . \overline{\mathrm{RMSE}}$ =2.9). A similar result was observed for NLME models $(\overline{\mathrm{RMSE}}=3.0 \mathrm{vs} . \overline{\mathrm{RMSE}}=3.6)$.

\subsubsection{Role of the time since restoration}

Whatever the form of the model considered (Table 4), permutation tests indicated that 10 channels are time-dependent (i.e., the null hypothesis is rejected at least at the $5 \% \alpha$-level) and gradually accumulated more and more fine sediment deposits after restoration. This result also highlights the presence of serial correlation in the observations of these side channels. The six other channels did not exhibit any significant time-dependent trajectories. We also found that CERI is a time-dependent side channel both in its restored and unrestored sections. 

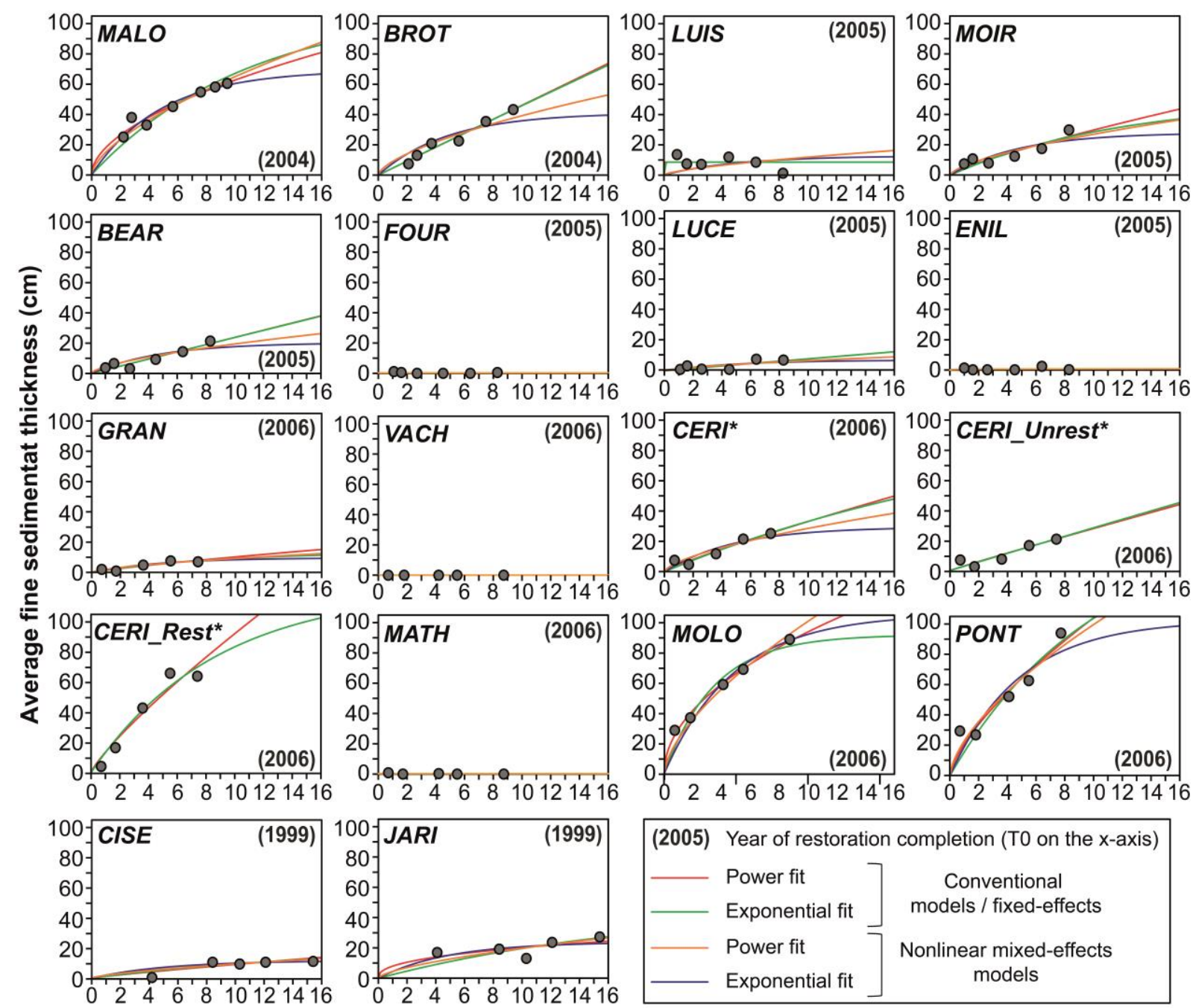

Time since restoration $(T+x$, years)

Fig. 10. Statistical relationships linking the average fine sediment thickness observed in side channels with the time since restoration (i.e., from $T 0$ to $T+\max$ ) according to four different models (see section 2.4.1 and Eqs. 2 and 3 for details). Raw data are available in Tables 1 and 2. *We split the data of CERI into three groups: the whole channel (CERI), the restored subsection 
Results of the four statistical models linking the channel-averaged fine sediment thickness observed in side channels with the time since restoration completion (T0); estimates of $\alpha$ and $\beta$ derived from our four models, and associated RMSE are displayed for each channel

553

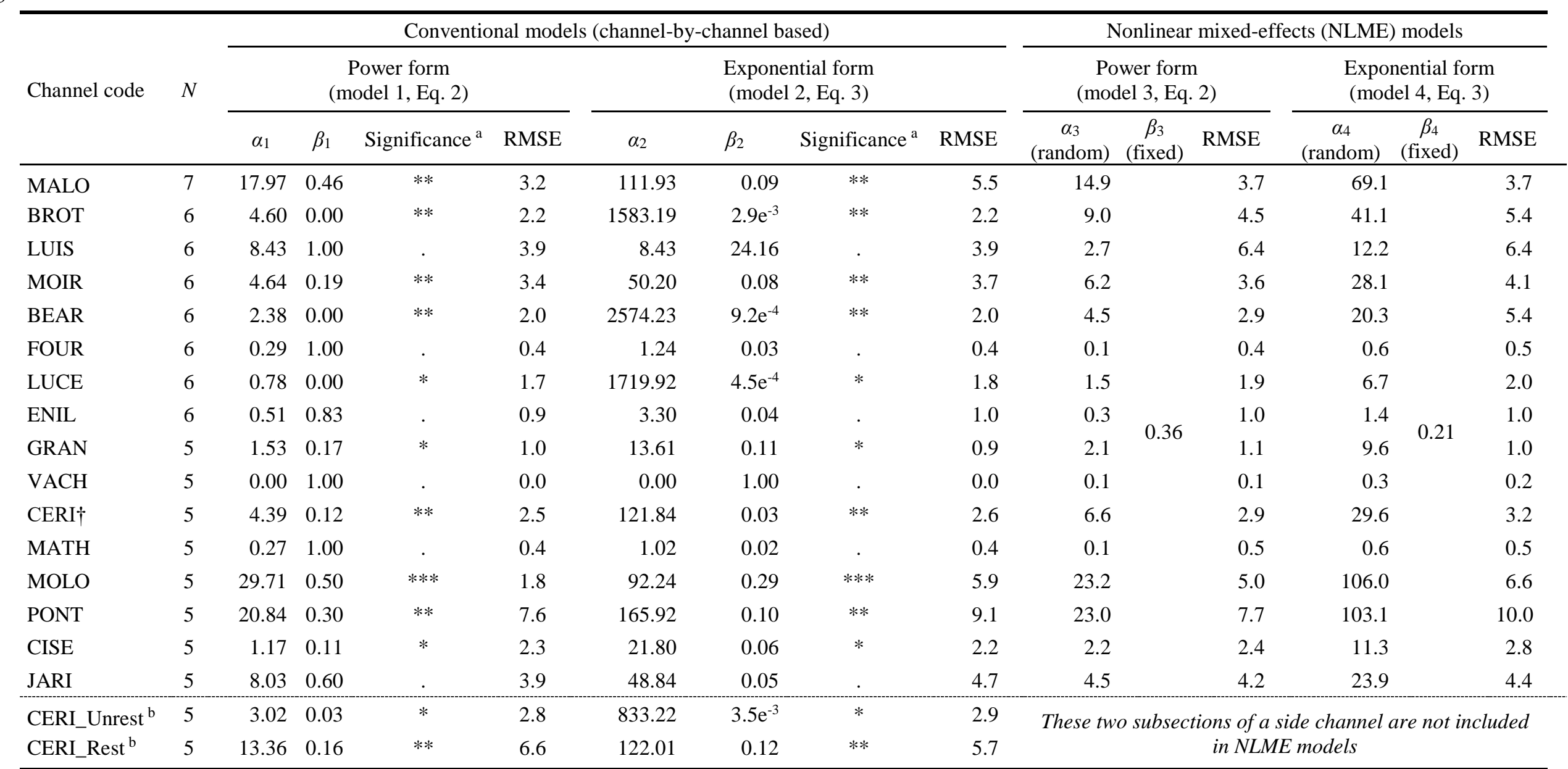

554 a Estimates are associated with the P-values resulting from our permutation test (test of the null hypothesis $\mathrm{H}_{0}$ : the time since restoration has no effect; see section 2.4.2 for 555 details): ".": P-value > 0.05; *: P-value <0.05; **: P-value < $0.01 ; * * *$ : P-value $<0.001$.

$556{ }^{\mathrm{b}}$ We split the data of CERI into three groups ( $c f$. Fig. 7): the whole channel (CERI), the restored subsection (CERI_Rest) and the unrestored subsections (CERI_Unrest). 
558 Restored channels have varied flooding regimes as depicted by values of annual upstream overflow

559 frequency, maximum shear stress, and maximum backflow capacity (Table 5). The upstream overflow 560 frequency for channels ranges from 0.24 d. $\mathrm{y}^{-1}$ (for BEAR) to 365.25 d.y ${ }^{-1}$ (e.g., for ENIL). The 561 maximum magnitude of upstream overflow events since restoration ranges from 2.6 (for MOLO) to $56254.1 \mathrm{~N} \cdot \mathrm{m}^{-2}$ (for BROT). The maximum backflow capacity ranges from 0.00 (e.g., for VACH) to 8.16 $563 \mathrm{~m} \cdot \mathrm{km}^{-1}$ (for PONT).

\section{$564 \quad$ Table 5}

565 Main physical features of side channel hydrology and hydraulics

\begin{tabular}{|c|c|c|c|c|c|}
\hline \multicolumn{2}{|c|}{ Side channels } & \multicolumn{4}{|c|}{ Hydrologic and hydraulic characteristics } \\
\hline $\begin{array}{c}\text { Reach } \\
\text { code }\end{array}$ & $\begin{array}{c}\text { Channel } \\
\text { code }\end{array}$ & 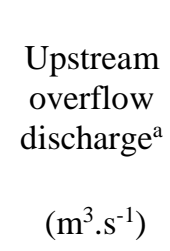 & $\begin{array}{l}\text { Upstream } \\
\text { overflow } \\
\text { frequency } \\
\qquad\left(\bar{f}_{Q b}\right) \\
\left(\mathrm{d} \cdot \mathrm{y}^{-1}\right)\end{array}$ & $\begin{array}{c}\text { Maximum } \\
\text { shear } \\
\text { stress }^{\mathrm{a}, \mathrm{b}} \\
\left(\bar{\tau}_{\text {max }}\right) \\
\mathrm{N} \cdot \mathrm{m}^{-2}\end{array}$ & $\begin{array}{l}\text { Maximum } \\
\text { backflow capacity } \\
\qquad\left(\overline{B f}_{\text {max }}\right) \\
\left(\mathrm{m} \cdot \mathrm{km}^{-1}\right)\end{array}$ \\
\hline CHAU & MALO & 989 & 0.37 & 7.7 & 7.09 \\
\hline CHAU & BROT & 1246 & 0.73 & 54.1 & 3.48 \\
\hline BELL & LUIS & 229 & 24.44 & $28.8^{c}$ & 0.00 \\
\hline BELL & MOIR & 417 & 8.55 & 6.5 & 1.13 \\
\hline BELL & BEAR & 982 & 0.24 & 25.4 & 3.74 \\
\hline BELL & FOUR & 167 & 38.48 & 36.7 & 0.46 \\
\hline BELL & LUCE & Perm. ${ }^{\mathrm{d}}$ & 365.25 & 27.0 & 0.00 \\
\hline BELL & ENIL & Perm. & 365.25 & 21.2 & 0.00 \\
\hline BREG & GRAN & 539 & 3.62 & 28.9 & 1.51 \\
\hline BREG & $\mathrm{VACH}$ & Perm. & 365.25 & 34.4 & 0.00 \\
\hline BREG & CERI & 102 & 179.48 & 17.0 & 0.00 \\
\hline BREG & MATH & Perm. & 365.25 & 27.7 & 0.00 \\
\hline BREG & MOLO & 560 & 4.59 & 2.6 & 6.56 \\
\hline BREG & PONT & 1266 & 1.10 & 4.8 & 8.16 \\
\hline PBE & CISE & Perm. & 365.25 & 33.1 & 0.00 \\
\hline PBE & JARI & 1801 & 4.86 & 21.3 & 3.88 \\
\hline
\end{tabular}

566

567

568

569

570

571

572 573

${ }^{\text {a }}$ See Riquier et al. (2015) for details regarding the determination of these values.

${ }^{\mathrm{b}}$ It corresponds to the post-restoration hourly maximum total boundary shear stress (i.e., a temporal maximum). Only values of side channels located in the bypassed reach of BELL have changed in comparison to those displayed in Riquier et al. (2015).

c The hourly maximum total boundary shear stress does not correspond to the maximum discharge for LUIS (ibid. for further details).

${ }^{\mathrm{d}}$ Perm.: permanent connection with the main channel for the minimum flow (100\% flow exceedance). 
When exploring the potential of these three metrics to predict fine sediment deposition, we used the $\alpha$ parameter derived from the power form of the NLME models (Table 4) as a proxy for the propensity of channels to accumulate fine deposits because the power form had been determined to be more efficient than the exponential form (see section 3.3.1). The $\alpha$ parameter is significantly negatively correlated to the annual upstream overflow frequency $\left(R^{2}=0.35 ; P<0.02\right.$; Fig. $\left.11 \mathrm{~A}\right)$, negatively correlated with the maximum shear stress $\left(R^{2}=0.69 ; P<10^{-5} ;\right.$ Fig. $\left.11 \mathrm{~B}\right)$, and positively correlated to the maximum backflow capacity $\left(R^{2}=0.80 ; P<10^{-6}\right.$; Fig. 11C). The $\alpha$ parameter is very well predicted from the combination of the maximum shear stress and the maximum backflow capacity (adjusted $R^{2}=0.86 ; P<0.006$ for $\bar{\tau}_{\text {max }}$ and $P<0.0003$ for $\overline{B f}_{\text {max }} ;$ Fig. 11D). We also tested to combine the upstream overflow frequency $\bar{f}_{Q b}$ with the maximum shear stress $\bar{\tau}_{\text {max }}$ and with the maximum backflow capacity $\overline{B f}_{\text {max }}$ (not displayed here). In the first case, we obtained good results ( $\alpha$ $=27.74-0.98 \log \left(\bar{f}_{Q b}\right)[P<0.03]-6.41 \log \left(\bar{\tau}_{\max }\right)\left[P<10^{-4}\right]$; adjusted $\left.R^{2}=0.76\right)$. In the second case, the upstream overflow frequency was only significant at the $10 \% \alpha$-level $(\alpha=-3.35+0.95 \log$ $\left(\bar{f}_{Q b}\right)[P=0.09]+3.09\left(\overline{B f}_{\text {max }}\right)\left[P<10^{-5}\right]$; adjusted $\left.R^{2}=0.82\right)$.

Types of fine sediment deposition patterns associated with channels are rather well discriminated, notably regarding channels of types A and D (Fig. 11). Channels of types B and C often show overlaps. Most type A channels are permanently connected at both ends to the main channel with high maximum shear stress values and no backflow capacity (VACH, MATH, and ENIL). The last one, FOUR, is a very high-energy and frequently overflowed channel that has a very low maximum backflow capacity. Type B channels (LUCE, GRAN, and BROT) exhibit a wide range of $\alpha$ values and flooding regimes. They have the highest within-type heterogeneity regarding values of $\alpha$.

595 BROT is the channel with the highest shear stress, but this backwater channel is relatively rarely 596 overflowed and has a high maximum backflow capacity (i.e., high sensitivity to settling processes).

597 LUCE and GRAN exhibit similar maximum shear stress conditions, which are relatively high. 598 However, LUCE is an active secondary channel showing a flooding regime similar to type A channel. 599 GRAN is a frequently overflowed backwater channel with a low maximum backflow capacity. 600 Similarly to type B channels, type C channels (LUIS, MOIR, BEAR, CERI, CISE, and JARI) show a 
601 wide range of sedimentary, hydrological, and hydraulic conditions. They exhibit the highest within602 type variability in terms of characteristics of the flooding regime, whichever metric is considered. All 603 are backwater channels, except for the active secondary channel of CISE. Their annual upstream 604 overflow frequency ranged from 0.24 (BEAR) to 365.25 d.y -1 $^{-1}$ (CISE). They exhibited maximum shear 605 stress values ranging from 6.5 (MOIR) to 33.1 N.m-2 (CISE). They had maximum backflow capacity 606 values ranging from 0.0 (CISE) to $3.88 \mathrm{~m} \cdot \mathrm{km}^{-1}$ (JARI). Type D channels are backwater channels that 607 are relatively rarely overflowed at their upstream end. They exhibit very low values of maximum shear 608 stress but have very high value of maximum backflow capacity. 


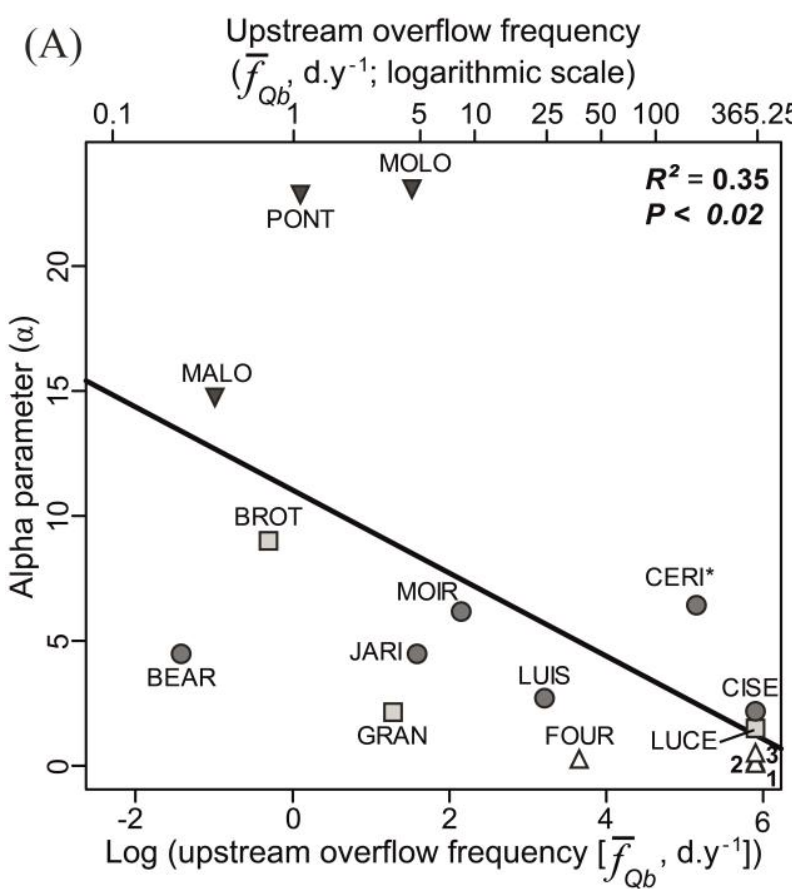

(C)

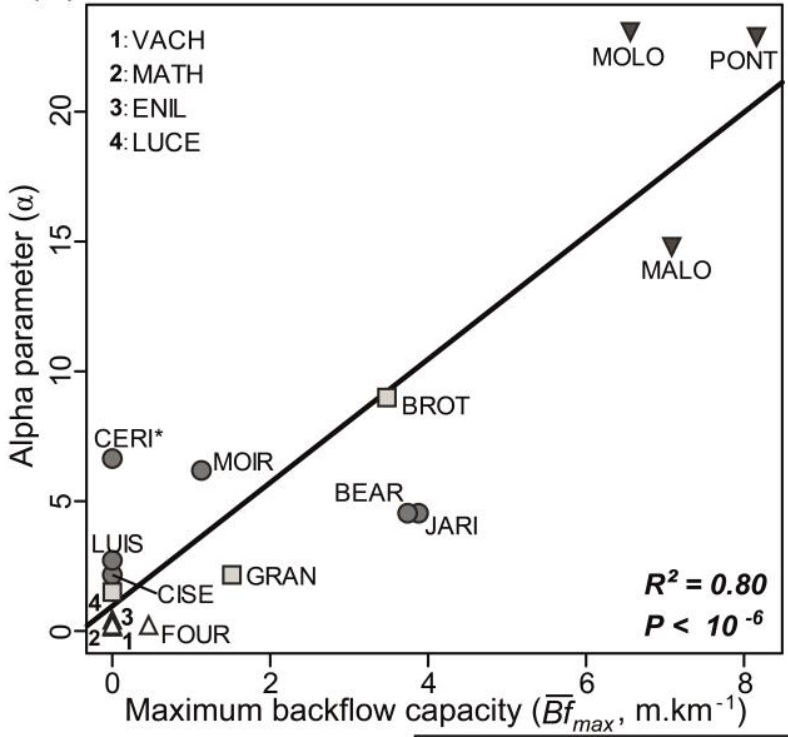

(B) Maximum hourly total boundary shear stress

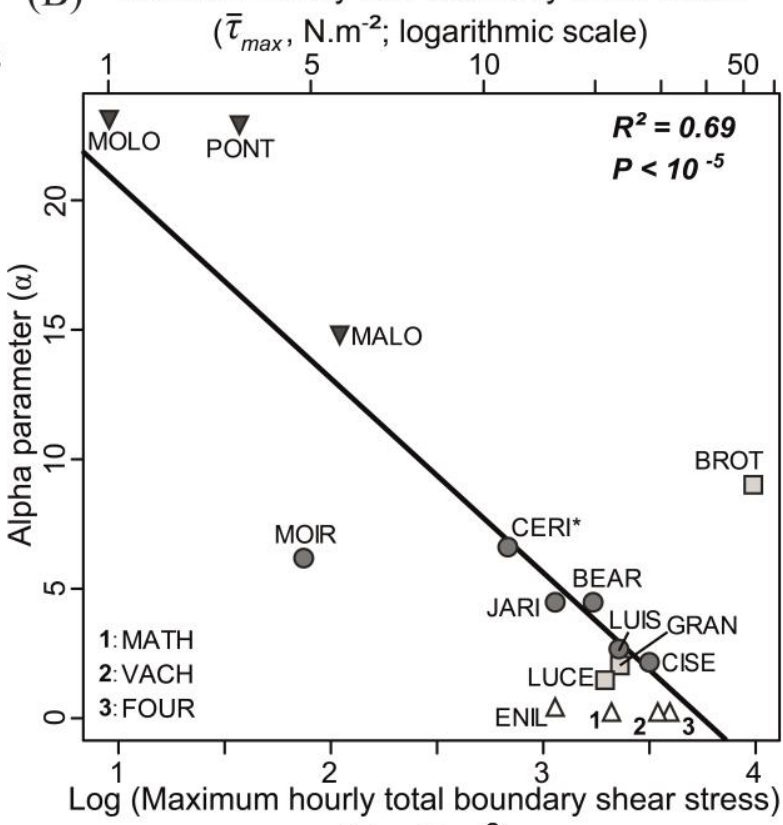

(D)

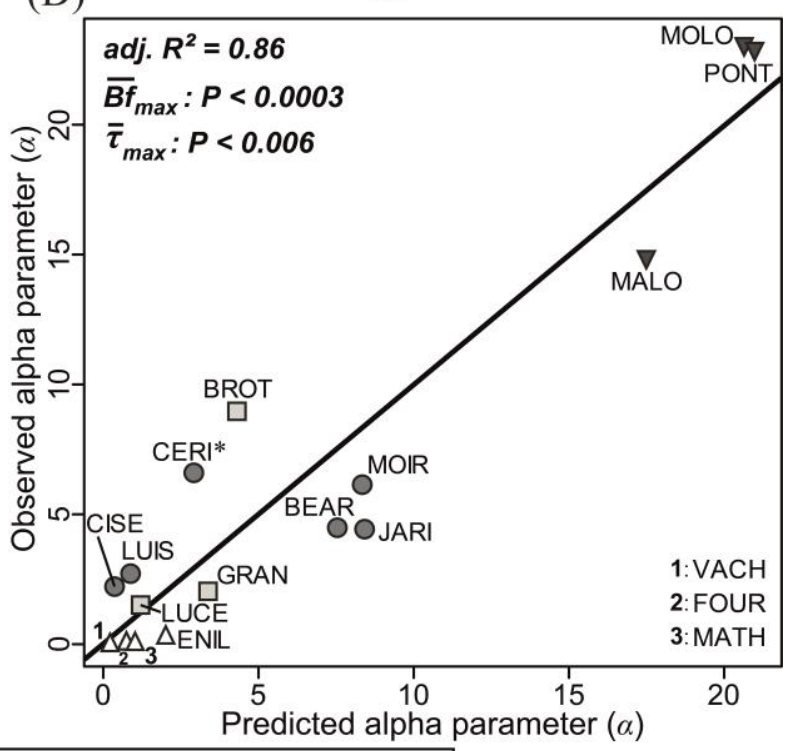

Time-averaged types of fine sedimentation pattern (cf. Fig. 7) $\triangle$ Type A $\square$ Type B OType C $\nabla$ Type D

Fig. 11. Predictions of fine sediment deposition over the post-restoration monitoring period. We used the $\alpha$ parameter derived from the power form of NLME models as a proxy for the response variable (raw values of $\alpha$ are displayed in Table 4 and raw values of the three explanatory variables tested are presented in Table 5). (A) Linear regression linking $\alpha$ with the annual upstream overflow frequency $\overline{\boldsymbol{f}}_{Q b}$, where $\alpha=$ 11.03 - $1.66 \log \left(\bar{f}_{Q b}\right)$. (B) Linear regression linking $\alpha$ with the maximum shear stress $\overline{\boldsymbol{\tau}}_{\text {max }}$, where $\alpha=$ 28.09 - $7.48 \log \left(\overline{\boldsymbol{\tau}}_{\text {max }}\right)$. (C) Linear regression linking $\alpha$ with the maximum backflow capacity $\overline{B f}_{\text {max }}$ (see Eq. 4), $\alpha=0.95+2.38\left(\overline{B f}_{\text {max }}\right)$. (D) Observed $v s$. predicted values of $\alpha$, where $\alpha$ is predicted from a linear combination of $\overline{B f}_{\text {max }}$ and $\bar{\tau}_{\text {max }}: \alpha=13.46-3.72 \log \left(\overline{\boldsymbol{\tau}}_{\text {max }}\right)+1.6\left(\overline{B f}_{\text {max }}\right)$.

Lines in bold depict the line of best-fit for $(\mathrm{A}),(\mathrm{B}),(\mathrm{C})$ and the line of perfect agreement for (D). Channels are discriminated according to their time-averaged types of fine sediment deposition patterns as shown in Fig 9. *Only the whole side channel of CERI is considered in this analysis. 
The four models previously established (Table 4; Fig. 10) were extrapolated through time in order to

624

625

626

627

628 assess the potential persistence of restored side channels as aquatic habitats (Fig. 12). We observed that these models can return different estimates for the same channel regarding its potential persistence as aquatic habitat over the long term.

Because they had been identified as time-independent channels (i.e., as channels a priori able to self-maintain their aquatic status over the long term), six channels (LUIS, FOUR, ENIL, VACH, MATH, and JARI) were not included in the analysis of Fig. 12. Three other channels seem to be able to maintain their aquatic stage to beyond a century (LUCE, GRAN, and CISE). This conclusion is based on projected channel-average fine sediment thickness being less than the initial average channel depth of the side channel (Fig. 12), regardless of the modeling approach considered (conventional or nonlinear mixed-effects) and their forms (power or exponential). The seven remaining channels can be separated into two groups: (i) BROT and BEAR on the one hand and (ii) MALO, MOLO, PONT, and MOIR on the other hand. CERI appears as a transitional form between these two latter groups.

Group (i) exhibits a very similar potential trend of adjustment according to the power and the exponential forms of the conventional models. Indeed, these side channels follow a near-linear trend (Fig. 12). Therefore, their rate parameter $\beta$ (channel-based) is very close to 0 for the two forms (see $\beta_{1}$ and $\beta_{2}$ for these channels in Table 4). The potential persistence of their aquatic stage according to the two forms of the conventional models ranges from 37 to 39 years after restoration for BROT and from 34 to 35 years for BEAR. The two forms of the NLME model suggest that the aquatic status of these two channels could be more sustainable because they use a higher value for the $\beta$ parameter $\left(\beta_{3}=0.36\right.$ [power form] and $\beta_{4}=0.21$ [exponential form]; $c f$. Table 4), which is fixed in the case of mixedeffects models (i.e., population-based and not computed at the channel level as it is for conventional models). According to the power form of the NLME model, the terrestrialization of BROT and BEAR will occur 99 and 93 years after restoration completion respectively. Finally, these two channels will quickly reach equilibrium with persistent aquatic habitat according to the exponential form of the NLME model. 
According to the two models that use the exponential form (i.e., conventional and NLME), the

650 channels in group (ii) will quickly reach a point of saturation. In other words, the fine sediment

651 thickness of these side channels would quickly reach equilibrium with persistent aquatic habitat:

652 discussion of such physically unrealistic trends will be developed below. Conversely, the two models

653 (i.e., conventional and NLME) that used the power form suggest that these channels could be rapidly

654 and completely filled with fine sediment. According to the power form of the conventional models,

655 MALO, MOIR, MOLO, and PONT will be terrestrialized 47, 51, 33, and 23 years after restoration

656 completion. According to the power form of the NLME model, they will be terrestrialized 35, 90, 23,

657 and 27 years after restoration.

658 CERI is a hybrid case between groups (i) and (ii). Values of $\alpha$ and $\beta$ derived from both forms 659 (power and exponential) of the conventional models are similar to those observed for channels of the 660 group (i) for the unrestored section of CERI (CERI_Unrest). Regarding the restored section 661 (CERI_Rest), values of $\alpha$ and $\beta$ are very close to those observed for channels of the (ii) group. 662 According to the conventional models, this channel and its subsections have the following expected 663 potential persistence (power and exponential forms, respectively): 32 and 44 years for the whole 664 channel of CERI, 33 and 32 years for CERI_Unrest, 12 and 22 years for CERI_Rest. According to the 665 power form of the NLME model, the whole channel of CERI will be terrestrialized 62 years after 666 restoration. Finally, its persistence as aquatic habitat according to the power form of the NLME model 667 is infinite. 

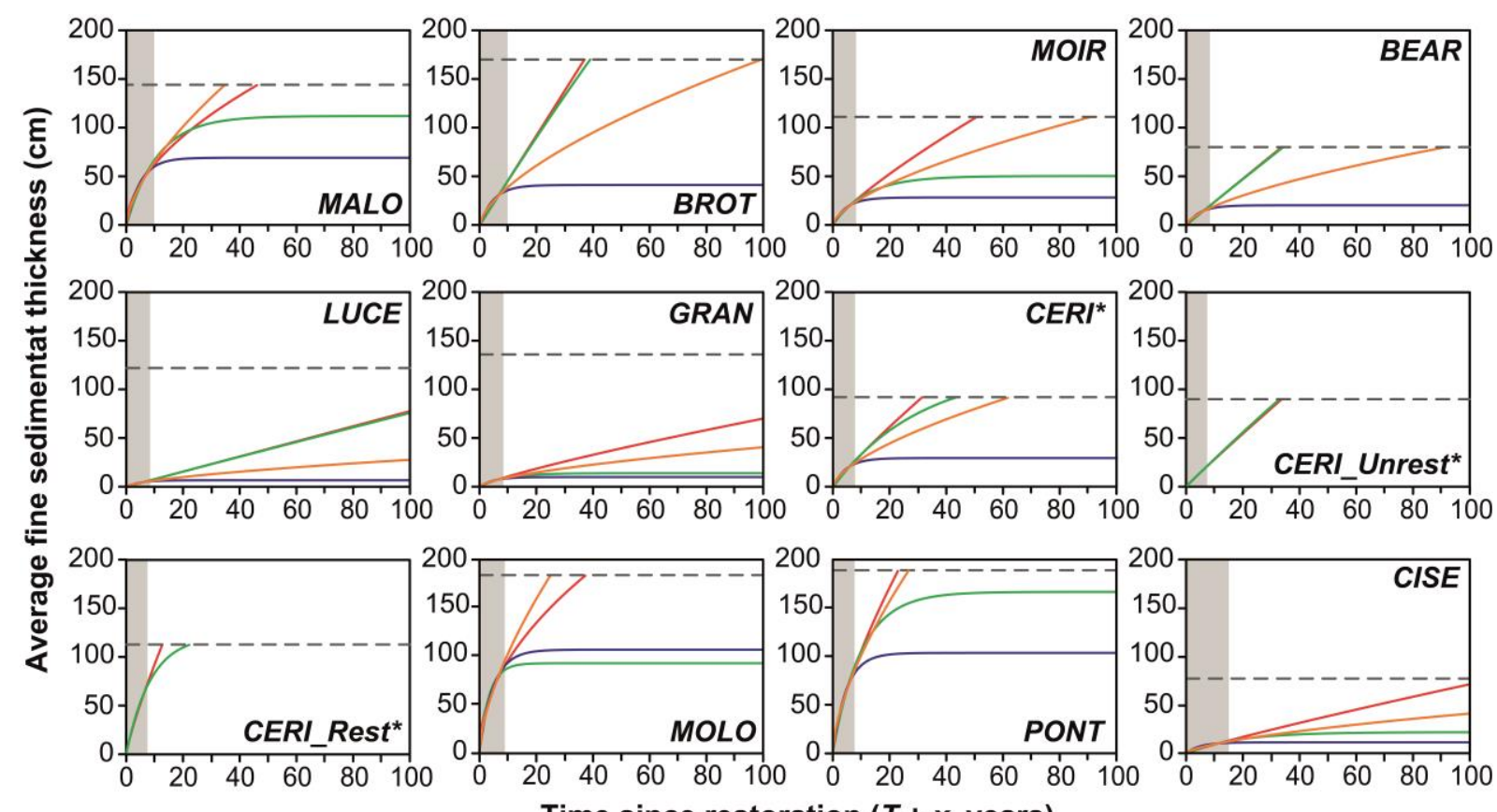

Time since restoration $(T+x$, years)

669

670

671

672

673

674

675

676

677

678

679

680

681

682

683

684

685

686

687

688

689

Fig. 12. Temporal extrapolation of statistical relationships linking the average fine sediment thickness observed in side channels with the time since restoration, which have been established in Fig. 10 for the T0-T+max time period (shaded time window). Only time-dependent side channels are displayed (cf. Table 4). Horizontal dashed lines show the initial average channel depth right after restoration (i.e., at T0). They refer to a reference water level corresponding to the minimal flow for side channels located in bypassed reaches and to the average discharge for channels located along the total Rhône (Table 1).

*We split the data of CERI into three groups: the whole channel (CERI), the restored subsection (CERI_Rest), and the unrestored subsections (CERI_Unrest). Subsections were not included in NLME models (cf. Table 2).

\section{Discussion}

Our results provide unique documentation on the fine sedimentation adjustment trajectories of 16 restored side channels, based on five to seven monitoring surveys ranging from T0 to 7-15 years after restoration, depending on the reach and the side channel considered. This time scale has allowed us to identify different sedimentation behaviors, model temporal trend, identify controlling factors, and propose empirical models to use a priori to improve restoration actions and to provide estimates of the potential persistence of restored side channels as aquatic habitats.

\subsection{Fine sedimentation evolution in space and time}

We identified four time-averaged types of post-restoration fine sediment deposition pattern (Fig. 9).

These types appeared to be partly controlled by the flooding regime and their sedimentary conditions 
690 are relatively stable through time over the monitored period so that they are robust. The extreme type

691 A and D channels are well discriminated from channels of the other types, whereas channels of types

692 B and C often show overlap with a wide range of flooding regimes (Fig. 11) and complex and 693 discontinuous longitudinal patterns of sedimentation (Fig. 9). They are different in the way type B 694 channels mainly experience sedimentation in their upstream sections where sedimentation in type C 695 channels is focused in their downstream sections. These differences in sedimentation patterns are 696 likely related to sediment processes that can be mainly linked to sand transport in type B channels with 697 a higher transport capacity during upstream overflow events; whereas backflows, diffusion, and 698 settlement of fines can play a more important role in type C channels. Nevertheless, both processes 699 affect channels of both types. This conclusion highlights the fact that additional major control(s) need to be incorporated to better distinguish these two intermediate types. Seemingly, hydraulic

701

702

703 characteristics within the side channel could play a substantial role, such as longitudinal changes in transport capacity (e.g., width and slope variations). Field reconnaissance provides some critical illustrations of the role of such a driving factor, notably on CISE where the high downstream sedimentation (Figs. 7 and 8) is observed in a much wider section than the one upstream.

Several studies have demonstrated that fine sediment deposition rates often decrease quickly through time (Hooke, 1995; Gautier et al., 2007; Kondolf and Stillwater Sciences, 2007; Riquier, 2015). In general, the frequency and intensity of upstream overflow and backflow events decrease as the channel closes off (i.e., gradual establishment of a downstream alluvial plug, elevation of the side channel bed because of sediment infill), so that fine sediment inputs and the potential occurrence of scouring processes also decrease. This trend is also observed in some restored side channels of the Rhône (Fig. 6), illustrating an aging pattern occurring soon after restoration. It is particularly obvious in Type D channels, which record the highest sedimentation rates (e.g., Fig. 11) and where we observe progressive construction of subaquatic alluvial plugs at their downstream ends following restoration. Additional investigations are needed to explore the boundary conditions responsible for the formation of downstream plugs in backwater channels.

Considering all channels of our study and only data of the last surveys (i.e., 2013 or 2014; time since restoration ranging from 7.4 to 15.4 years), channel-averaged fine sediment deposition rates 
ranged from 0 to $13.6 \mathrm{~cm} \cdot \mathrm{y}^{-1}$. These rates seem rather high in comparison to values reported in other studies and notably the ones conducted in the region. Piégay et al. (2008) observed rates ranging from 0.65 to $2.4 \mathrm{~cm} . \mathrm{y}^{-1}$ in 14 former braided, meandering, and wandering channels of the Ain River (France) (ages ranging from 10 to 40 years after trees establishment). Citterio and Piégay (2009) measured rates ranging from 0 to $2.57 \mathrm{~cm} \cdot \mathrm{y}^{-1}$ in 39 former anastomosis, braided, meandering, and wandering channels situated in the Ain, the Doubs, and the Rhône rivers (France) (ages ranging from 25 to 300 years following cutoff or isolation of the upstream end). Reckendorfer et al. (2013) estimated rates ranging from 0.5 to $2.8 \mathrm{~cm} \cdot \mathrm{y}^{-1}$ in 16 former braided or anabranched channels of the Danube River (Austria), aged of about a century (computed in reference to embankments construction that partially isolated them from the main channel). Rates observed here are closer to those reported by Stella et al. (2011) with rates ranging from 4 to $18 \mathrm{~cm} \cdot \mathrm{y}^{-1}$ in 10 oxbows with varied ages (from 15 to 100 years after cutoff) of the Sacramento River (USA) or Erskine et al. (1992) with rates ranging from 4.5 to $14 \mathrm{~cm} \cdot \mathrm{y}^{-1}$ in three oxbows of the Hunter River (Australia) with ages ranging from 50 to 100 years, where suspended sediment concentration are much more important than in rivers flowing from the European Alps.

We observed that most of the side channels, except MOLO, are regularly scoured during relatively frequent flood flows (2 to 5 year floods; Table 2; Fig. 2), regardless of their time-averaged type. We also found that six side channels are not time-dependent in terms of sedimentation (Table 4; Fig. 10) and are thus self-sustaining. Ten other side channels were found to be time-dependent and have a general trajectory toward terrestrialization despite being subject to regular erosional processes. Scouring events were not powerful enough to allow their self-maintenance. Nonetheless, we still need to observe how they will react to less frequent, larger magnitude flood flows than those that have been experienced so far (Fig. 2). Flood-scouring processes are often sought in the design of side channels but have rarely been quantified. These processes are critical because they determine the ability of restored side channels to maintain their aquatic status over time (Henry and Amoros, 1995; Amoros et al., 2005). Thus, they sustain the effects of restoration actions over time and contribute to the longterm success of such restoration projects. 
Restoration primarily modifies forms, but for most side channels, processes such as upstream

overflow frequency and magnitude are relatively close to conditions that prevailed before restoration.

With the exception of channels that were fully reconnected (4/16 channels), the geometry of upstream alluvial plugs were not modified. In many cases, excavation of side channels increases their ability to store fine sediment (see section 3.1.2). This trend is particularly pronounced because most channels were perched above the channel before restoration, because of dewatering resulting from the incision of the main river bed and flow diversion. Notably, this increase in the trapping efficiency of channels is largely compensated by the substantial increase in water depth resulting from restoration.

\subsection{Role of the flooding regime and implications of side channel geometry}

754

To date, few studies have successfully linked fine sediment deposition rates with quantitative descriptors of the flooding regime of side channels using statistical analysis. Exceptions include studies by Piégay et al. (2000, 2008) and Citterio and Piégay (2009) who considered fine sediment deposition rates as a function of the balance between two opposing processes: the upstream and the downstream overflow frequency of side channels. These metrics are used as proxies for the potential for fine sediment scouring resulting from upstream overflow events versus the potential for net sedimentation resulting from backflow events respectively. Our results provide additional support regarding the effect of the hydrological connectivity during flood events, notably regarding the implication of the magnitude of upstream overflow (i.e., maximum shear stress) and backflow events (i.e., maximum backflow capacity). We found that the capacity of channels to sequester fine sediment deposits is significantly and inversely related to maximum shear stress (Fig. 11B) and significantly and directly related to maximum backflow capacity (Fig. 11C). In this regard, the maximum shear stress is a good proxy for the sediment transport capacity of side channels. The maximum backflow capacity is a good proxy for the fine sediment trapping efficiency of channels. Therefore, the combination of these two metrics significantly improves the prediction of sedimentation (Fig. 11D). Conversely, we found that upstream overflow frequency (Fig. 11B) is a poor predictor when considered alone and thus needs to be considered in combination with other factors that modulate its effect on fine sediment accumulation/erosion. For example, the relationship between the propensity to 
accumulate fine sediment and the upstream overflow frequency is not evident in the BEAR side channel (high negative residual in Fig. 11A). This channel is rarely overflowed, but it shows high stress values when connected at its upstream end to the main channel (Fig. 11B). Thus, this channel does not fit the model because of its high scouring capacity. For MOLO and PONT, upstream overflow events have little effect on fine sediment accumulation (high positive residuals in Fig. 11A) because they have low stress values (Fig. 11B). Therefore, independently of the upstream overflow frequency, these two channels accumulate a large amount of fine material because they have a very high maximum backflow capacity (Fig. 11C) so that they trap a lot of fines through settling processes during upstream overflow events and during backflow events. BROT is also a good example to demonstrate the need to consider several factors at the same time. This channel has the highest shear stress value (Fig. 11B). Nevertheless, it has a high capacity to sequester fines because it is relatively rarely overflowed at its upstream end (Fig. 11A), and it has a high maximum backflow capacity.

The results in Fig. 11 suggest that sedimentation in restored side channels in the first decades after restoration can be well predicted, using relatively simple hydrological and/or hydraulic descriptors (annual upstream overflow frequency, maximum shear stress, and maximum backflow capacity) that reflect the geometric controls on their flooding regime (e.g., morphology of the upstream alluvial plug, slope conditions). Compared to previous studies (ibid.), a major practical advance is reached here because managers can quantify a priori these metrics and modify and/or target their actions accordingly. By allowing the quantification of how technical decisions relative to the design of channels can affect their sedimentation, empirical relationships developed in this study can be used for guiding the design of future restoration sites or for implementing adaptive management in the Rhône River context. Managers can now take advantage of these models to maximize the sustainability of restoration actions and habitat diversity when considering previous ones (Riquier et al., 2015). The new challenge is now to see if such models can be applied to other river systems and in which hydromorphological conditions. 
798

799

800

801

802

803

804

805

806

807

808

809

810

811

812

813

814

815

816

The predictive accuracy of our models is limited by assumptions and simplifications. The main ones are formulated below. First of all, we assumed that terrestrialization processes are driven only by fine sediment accumulation. However, side channel water levels can be affected by other factors such as main channel degradation/aggradation or enlargement/narrowing (Bornette and Heiler, 1994; Bravard et al., 1997; Piégay et al., 2000, 2008). The development of dense vegetation patches can also slow down flow velocities and promote sediment trapping (e.g., Steiger et al., 2005). By extrapolating trends estimated over the post-restoration period, we assumed the history of flow and sediment load and underlying processes in restored channels (erosion/deposition) will be similar to what was observed from $T 0$ to $T+\max$, but we do not yet know how restored side channel would react to less frequent flood flows $\left(\mathrm{Q}_{5}<\mathrm{x}<\mathrm{Q}_{20}\right.$, depending on the reach considered; Fig. 2). Another important aspect concerns the use of channel-averaged values of fine sediment thickness. Indeed, sedimentation patterns are rarely homogeneous along the length of channels (e.g., Figs. 7 and 8), meaning that some channel subsections can have very distinctive differences in terms of potential persistence in comparison to the spatially averaged one. Finally, we used measures of fine sediment thickness performed along the channels' centerline length. As a consequence, fine sediment deposits from the centerline to the banks of channels were not considered in our estimations, assuming sedimentation rates are similar along the transversal dimension of channels. Further research is needed to explore all these issues. However, even with understanding of these identified limitations, ranges of channel potential persistence are often consistent with their hydrodynamic behavior. Extrapolated trends derived from the four tested models allowed us to show the range of uncertainty existing for some of these estimations (Fig. 12). However, some trajectories of adjustment are not physically consistent for all channels. In the following, realistic or unrealistic trends are discussed regarding types of adjustment previously identified. Estimated potential persistence of restored side channels as aquatic habitats are summarized in Table 6.

Six side channels (LUIS, FOUR, ENIL, VACH, MATH, and JARI) do not exhibit any significant time-dependent trajectories (Table 4; Fig. 10). Among the 10 others, which are time- 
dependent, three are high life-duration channels (LUCE, GRAN, and CISE). These three channels have a rather high scouring capacity, which slowed down fine sediment accumulation through time without completely reversing the process. They seem to be capable of maintaining their aquatic status for more than a century, whichever the models (conventional or nonlinear mixed-effects) and forms (power or exponential) are considered (Fig. 12). These channels are likely to follow an oscillating trajectory between the trend suggesting shorter persistence (i.e., the power form of the conventional models) and the trend suggesting longer persistence (the exponential form of the NLME models). Three other channels (BEAR, BROT, and MOIR) can be considered as intermediate life-duration channels (persisting from about three to nine decades). BEAR and BROT channels have a high maximum backflow capacity. They are also rarely overflowed at their upstream end but can undergo high shear stress during flood pulses. These channels followed near linear trajectories over the postrestoration monitoring period (Fig. 12; Table 2) and recorded relatively consistent sedimentation rates through time (Figs 5 and 10). Therefore, the exponential form of NLME models (Fig. 10), which suggests that these channels can reach equilibrium, is probably unrealistic. It depends largely on whether or not a greater frequency of large floods will occur in the coming decades. MOIR is close to these two channels in terms of potential life span, but its hydrodynamic functioning differs a lot from them. This channel has a medium upstream overflow frequency combined with low shear stress and low maximum backflow capacity. Thus, the rejuvenation capacity of this channel is relatively low, so that reaching equilibrium with persistent aquatic habitat is not a realistic trend for this channel. Therefore, only the power forms of conventional and NLME models provided a realistic range of potential persistence for this channel. The sustainability of these three intermediate life-duration channels is likely to be very dependent on whether sedimentation rates decrease through time or not (see section 4.1). As noted for high life-duration channels, they are likely to follow an oscillating trajectory between the trend suggesting shorter persistence and the trend suggesting longer persistence. The amplitude of the oscillations will depend on the magnitude of sedimentation/scouring events. Three other channels (MALO, MOLO, and PONT) can be considered as low life-duration channels (likely from about two to five decades). These exclusively type D channels (Fig. 9) have a very low scouring capacity and very high fine sediment trapping efficiency, which tended to decrease through 
852 time owing to the formation of alluvial plugs at their downstream end. Obviously, the propensity to

853 accumulate fine sediment of these channels is so important that they cannot reach equilibrium with

854 persistent aquatic habitat. Trajectories derived from exponential forms of the two models displayed in

855 Fig. 12 (i.e., conventional and NLME) constitute physically unrealistic trends. Therefore, the power 856 forms of conventional and NLME models provided a realistic range of the potential persistence of these channels: i.e., from 47 to 35 years for MALO, from 33 to 23 years for MOLO, and from 23 to 27 years for PONT.

Finally, CERI constitutes a specific case. The restoration of CERI included only minor improvement. The channel was dredged locally ( $c a .100 \mathrm{~m}$ of the $920 \mathrm{~m}$ of the side channel). Only conventional models were fitted for the restored (CERI_Rest) and the unrestored (CERI_Unrest) sections of CERI. These subreaches have an estimated potential persistence ranging from 12 to 22 years for the restored one and from 33 to 32 years for the unrestored one (according to the power and exponential forms of the conventional models). The whole channel of CERI is unlikely to reach equilibrium with persistent aquatic habitat as suggested by the power form of the NLME models. Its estimated life span ranges from 31 to 52 years, according to the power forms of the conventional and NLME models (respectively). According to our classification, CERI is a low life-duration channel. Nevertheless, the unrestored section of this side channel is relatively old (cutoff between 1860 and 1930). We also observed few deposits of fine sediment before the survey of 2009 and subsequent ones (Table 2; Figs. 5 to 8). In addition, this channel was very frequently overflowed at its upstream end. It had a very low maximum backflow capacity and intermediate shear stress (Fig. 11). These elements suggest CERI is likely to be able to scour deposits of fines during relatively infrequent floods so that our current estimates probably minimize its effective life span. Thus, this channel is likely to follow a slow oscillating trajectory toward terrestrialization over the long term. Therefore, it can be considered as a high life-duration channel. 


\begin{tabular}{lllllllll}
\hline & MALO & BROT & LUIS & MOIR & BEAR & FOUR & LUCE & ENIL \\
\cline { 2 - 8 } & $35-47$ & $34-99$ & $\begin{array}{l}\text { Self- } \\
\text { sust. }\end{array}$ & $51-90$ & $35-93$ & Self-sust. & $>100$ & Self-sust. \\
\cline { 2 - 8 } $\begin{array}{l}\text { Estimated } \\
\text { potential life } \\
\begin{array}{l}\text { span of side } \\
\text { channels } \\
(\text { Years })\end{array}\end{array}$ & GRAN & VACH & CERI & MATH & MOLO & PONT & CISE & JARI \\
\cline { 2 - 8 } & $>100$ & Self-sust. & $31-52$ & Self-sust. & $21-32$ & $17-22$ & $>100$ & Self-sust.
\end{tabular}

\footnotetext{
${ }^{a}$ Self-sust.: self-sustainable.
}

All these estimated life spans for restored side channels need to be considered carefully for the reason listed above. Moreover, such extrapolation of trajectories can be sensitive to the number and the temporal extent of observations. For example, Amoros et al. (2005) estimated that the JARI side channel is not self-sustaining: assuming a sedimentation rate varying between 3 and $5 \mathrm{~cm} \cdot \mathrm{y}^{-1}$ and a remaining average water depth of $120 \mathrm{~cm}$, they estimated the persistence of this channel between 30 and 46 years in reference to restoration completion. In the present study, we observed that JARI recorded relatively high fine sediment deposition rates but that they quickly decreased through time such that statistical evidence suggested that the channel could be self-sustaining. Indeed, this channel seems to have reached a pseudo steady-state between depositional and erosional processes (Table 4). It highlights the intrinsic uncertainty of such approaches. More generally, such different conclusions emphasize the need for restoration projects to be subject to long term monitoring (see also Morandi et al., 2014) as the basis for more reliable and robust empirical relationships. Finally, we used four models as alternative smoothers to estimate trends in fine sediment accumulation. One could fit a wide variety of other parametric models to these data. In this respect, continuing the monitoring of side channels over the long term will allow us to determine which ones are the best smoothers.

\section{Conclusion}

We observed a high variability of fine sediment deposition patterns and rates in space (i.e., within and between the 16 restored channels studied) and in time (i.e., from restoration to the last survey). The side channels also have diverse potential persistence as aquatic habitats. We demonstrated that postrestoration channel-averaged sedimentation rates could be predicted from simple flooding regime metrics such as the upstream overflow frequency, maximum shear stress, and maximum backflow 
903

904

905

906

907

908

909

910

911

912

913

914

915

916

capacity. These results also illustrate the importance of long-term monitoring to help us describe and understand the evolutionary trajectories of restored side channels. We also still need to test other controls on the persistence of side channels as aquatic habitats, such as their infilling by bedload for the most energetic channels or also potential changes of base levels that can affect the water depth independently of fine sediment accumulation.

The flooding regime metrics established here can be calculated prior to restoration and used to guide project designs. Such calculations could assist in reducing the uncertainty about the postrestoration evolution of side channels and help optimize the balance between sustainability of restoration actions, local ecological gains, and restoration costs. Our empirical statistical relationships, as well as the typological framework developed, are then of considerable interest for managers.

Further developments are needed to improve the practical use of our statistical models. For example, we still need to test their transferability to other side channel types (e.g., oxbows) and to other fluvial systems with sediment loads that differ from the one observed in the Rhône River. We still must improve our understanding of key physical processes, notably regarding the shear stress for critical motion of fine sediment deposits; the dynamic of backflows and the effect of longitudinal distance to the main channel on sediment diffusion processes; the influence at a finer scale of other morphological features, such as the long profile of the side channel bed and width of the side channels; and the establishment of downstream alluvial plugs, or the effect of groundwater supply.

\section{Acknowledgements}

This study was funded by the Compagnie Nationale du Rhône, the Agence de l'Eau RhôneMéditerrannée-Corse, the Region Provence-Alpes-Côte-d'Azur, the Région Rhône-Alpes, the Rhône local authorities, Electricité de France, the EU FEDER program in the context of the RhonEco research program, the OHM Vallée du Rhône, and the LabEx DRIIHM. We gratefully acknowledge Jean-Michel Olivier for the co-coordination of the scientific monitoring of the Rhône restoration programme. We thank Robin Jenkinson for her helpful linguistic support. We thank Peter Downs,

Richard Marston and an anonymous reviewer for their constructive comments and suggestions. Finally, we are grateful to the many colleagues involved during the past 10 years in the monitoring of 
931

932

933

934

935

936

937

938

939

940

941

942

943

944

945

946

947

948

949

950

951

952

953

954

955

956

957

958

these channels and particularly Johan Berthet, Ludovic Bultingaire, Thomas Dépret, Guillaume

Fantino, Rémi Foussadier, Loïc Grosprêtre, Julien Levrat, Bertrand Morandi, Volodia Petropavlovsky, Magalie Rival, Samuel Segura, and Monika Šulc Michalková.

\section{References}

Amoros, C., Bornette, G., Henry, C.P., 2000. A Vegetation-Based Method for Ecological Diagnosis of Riverine Wetlands. Environ. Manage. 25, 211-227.

Amoros, C., Elger, A., Dufour, S., Grosprêtre, L., Piégay, H., Henry C., 2005. Flood scouring and groundwater supply in side-channel rehabilitation of the Rhône River, France: sedimentation and aquatic vegetation responses. Arch. Hydrobiol. Supplementband 155, 147-167.

Baptist, M.J., Penning, W.E., Duel, H., Smits, A.J., Geerling, G.W., Van der Lee, G.E., Van Alphen J.S., 2004. Assessment of the effects of cyclic floodplain rejuvenation on flood levels and biodiversity along the Rhine River. River Res. Appl. 20, 285-297.

Bornette, G., Heiler, G., 1994. Environmental and biological responses of former channels to river incision: A diachronic study on the Upper Rhône River. Regul. River. 9, 79-92.

Bravard, J.-P., 1987. Le Rhône du Léman à Lyon. La Manufacture, Lyon, 451 p.

Bravard, J.-P., 2010. Discontinuities in braided patterns: the River Rhône from Geneva to the Camargue delta before river training. Geomorphology 117, 219-233.

Bravard, J.-P., Amoros, C., Pautou, G., 1986. Impact of civil engineering works on the successions of communities in a fluvial system. A methodological and predictive approach applied to a section of the Upper Rhône River, France. Oikos 47, 92-111.

Bravard, J.-P., Amoros, C., Pautou, G., Bornette, G., Bournaud, M., Creuzé des Châtelliers, M., Gibert, J., Peiry, J.-L., Perrin, J.-F., Tachet, H., 1997. River incision in south-east France: morphological phenomena and ecological effects. Regul. River. 13, 75-90.

Chessel, D., Dufour, A.B., Thioulouse J., 2004. The ade4 package-I: One-table methods. R News 4, 510.

Citterio, A., Piégay, H., 2009. Overbank sedimentation rates in former channel lakes: characteristization and control factors. Sedimentology 56, 461-482. 
Constantine, J.A., Dunne, T., Piégay, H., Kondolf, G.M., 2010. Controls on the alluviation of oxbow lakes by bed material load along the Sacramento River, California. Sedimentology 57, 389-407.

Dépret, T., Riquier, J., Piégay, H., in press. Evolution of abandoned channels: insights on controlling factors in a multi-pressure river system. Geomorphology, DOI: 10.1016/j.geomorph.2017.01.036.

Dieras, P., 2013. The persistence of oxbow lakes as aquatic habitats: An assessment of rates of change and patterns of alluviation. Ph.D. Thesis, Cardiff University.

Erskine, W., McFadden, C., Bishop, P., 1992. Alluvial cutoffs as indicators of former channel conditions. Earth Surf. Process. Landf. 17, 23-37.

Gagliano, S.M., Howard, P.G., 1984. The neck cutoff oxbow lake cycle along the Lower Mississippi River. In: Elliot, E.C.M. (Ed.), River Meandering. American Society of Civil Engineers, New York, pp. 147-158.

Gautier, E., Brunstein, D., Vauchel, P., Roulet, M., Fuertes, O., Guyot, J.-L., Darozzes, J., Bourrel, L., 2007. Temporal relations between meander deformation, water discharge and sediment fluxes in the floodplain of the Rio Beni (Bolivian Amazonia). Earth Surf. Process. Landf. 32, 230-248.

Gaydou, P., 2013. Schéma directeur de réactivation de la dynamique fluviale des marges du Rhône. Synthesis report, Observatoire des Sédiments du Rhône, Lyon.

Henry, C.P., Amoros, C., 1995. Restoration ecology of riverine wetlands: I. A scientific base. Environ. Manage. 19, 891-902.

Hohensinner, S., Jungwirth, M., Muhar, S., Schmutz, S., 2014. Importance of multidimensional morphodynamics for habitat evolution: Danube River 1715-2006. Geomorphology 215, 3-19.

Hooke, J.M., 1995. River channel adjustment to meander cutoffs on the river Bollin and river Dane, northwest England. Geomorphology 14, 235-253.

Jacobson, R.B., Galat, D.L., 2006. Flow and form in rehabilitation of large-river ecosystems: an example from the Lower Missouri River. Geomorphology 77, 249-269.

Jacobson, R.B., Laustrup, M.L., Chapman, M.D., 2001. Fluvial processes and passive rehabilitation of the Lisbon Bottom side channel chute, Lower Missouri River. In: Dorava, J.M., Montgomery, D.R., Palcsak, B.B., Fitzpatrick, F.A. (Eds.), Geomorphic Processes and Riverine Habitat. 

American Geophysical Union, Water Science and Application Series, Volume 4, Washington DC, pp. 199-216.

Jacobson, R.B., Johnson, H.E., Laustrup, M.S., D'Urso, G.J., Reuter, J.M., 2004. Physical habitat dynamics in four side-channel chutes, Lower Missouri River. Geological Survey Open-File Report 2004-1071.

Klingeman, P.C., Bravard, J.P., Giuliani, Y., Olivier, J.M., Pautou G., 1998. Hydropower reach bypassing and dewatering impacts in gravel-bed rivers. In: Klingeman, P.C., Beschta, R., Komar, P., Bradley J. (Eds), Gravel Bed Rivers in the Environment. Water Resources Publications, Littleton, pp. 313-344.

Kleinhans, M.G., Ferguson, R.I., Lane, S.N., Hardy, R.J., 2013. Splitting rivers at their seams: bifurcation and avulsion. Earth Surf. Process. Landf. 38, 47-61.

Kondolf, G.M., Stillwater Sciences, 2007. Sacramento River Ecological Flows Study: Off-Channel Habitat Study Results. Technical report prepared for The Nature Conservancy, Chico, $190 \mathrm{p}$.

Lamouroux, N., Gore, J.A., Lepori, F., Statzner B., 2015. The ecological restoration of large rivers needs science-based, predictive tools meeting public expectations: an overview of the Rhône project. Freshw. Biol. 60, 1069-1084.

Morandi, B., Piégay, H., Lamouroux, N., Vaudor, L., 2014. How is success or failure in river restoration projects evaluated? Feedback from French restoration projects. J. Environ. Manage. 137, pp. 178-188.

Olivier, J.-M., Carrel, G., Lamouroux, N., Dole-Olivier, M.-J., Malard, F., Bravard, J.-P., Amoros, C., 2009. The Rhône River basin. In: Tockner, K., Robinson, C.T., Uehlinger U. (Eds.), Rivers of Europe. Elsevier, Amsterdam, pp. 247-295.

Piégay, H., Bornette, G., Citterio, A., Hérouin, E., Moulin, B., Statiotis, C., 2000. Channel instability as control factor of silting dynamics and vegetation pattern within perifluvial aquatic zones. Hydrol. Process. 14, 3011-3029.

Piégay, H., Bornette, G., Grante, P., 2002. Assessment of silting-up dynamics of eleven cut-off channel plugs on a free-meandering river (Ain River, France). In: Allison, R.J. (Ed.), Applied Geomorphology: Theory and Practice. John Wiley and Sons, Chichester, pp. 227-247. 
1015 Piégay, H., Hupp, C.R., Citterio, A., Dufour, S., Moulin, B., Walling, D.E. (2008). Spatial and

1016

1017

1018

1019

1020

1021

1022

1023

1024

1025

1026

1027

1028

1029

1030

1031

1032

1033

1034

1035

1036

1037

1038

1039

1040

1041

1042 temporal variability in sedimentation rates associated with cutoff channel infill deposits: Ain River, France. Water Resour. Res. 44, W05420.

R Core Team, 2016. R: A Language and Environment for Statistical Computing. R Foundation for Statistical Computing.

Reckendorfer, W., Schmalfuss, R., Baumgartner, C., Habersack, H., Hohensinner, S., Jungwirth, M., Schiemer, F., 2005. The Integrated River Engineering Project for the free-flowing Danube in the Austrian Alluvial Zone National Park: contradictory goals and mutual solutions. Arch. Hydrobiol. Supplementband 155, 613-630.

Reckendorfer, W., Funk, A., Gschöpf, C., Hein, T., Schiemer F., 2013. Aquatic ecosystem functions of an isolated floodplain and their implications for flood retention and management. J. Appl. Ecol. 50, 119-128.

Riquier, J., 2015. Réponses hydrosédimentaires de chenaux latéraux restaurés du Rhône français. Structures spatiales et dynamiques temporelles des patrons et des processus, pérennité et recommandations opérationnelles. Ph.D. Thesis, Université Lumière Lyon 2.

Riquier, J., Piégay, H., Sŭlc Michalkova M., 2015. Hydromorphological conditions in eighteen restored floodplain channels of a large river: linking patterns to processes. Freshw. Biol. 60, 1085-1103.

Rostan, J.-C., Amoros, C., Juget J., 1987. The organic content of the surficial sediment: a method for the study of ecosystems development in abandoned river channels. Hydrobiologia 148, 45-62.

Roux, A.-L., Bravard, J.-P., Amoros, A., Pautou, G., 1989. Ecological changes of the French Upper Rhône River since 1750. In : Petts, G.E., Möller, H., Roux, A.-L. (Eds.), Historical change of large alluvial rivers: Western Europe. John Wiley and Sons, Chichester, pp. 323-350.

Shields Jr., F.D., Abt, S.R., 1989. Sediment deposition in cutoff meander bends and implications for effective management. Regul. River. 4, 381-396.

Shields Jr., F.D., Knight, S.S., Stofleth, J.M., Wren D.G., 2009. Towards a basis for designing backwater and side channel restorations. Proceedings of the International Association for Hydraulic Research 33rd Congress. IAHR, Madrid, pp. 5710-5717. 
1043 Simons, J.H.E.J., Bakker, C., Schropp, M.H.I., Jans, L.H., Kok, F.R., Grift, R.E., 2001. Man-made secondary channels along the River Rhine (The Netherlands); results of post-project monitoring. Regul. River. 17, 473-491.

1046

Stammel, B., Cyffka, B., Geist, J., Müller, M., Pander, J., Blasch, G., Fischer, P., Gruppe, A., Haas, F., Kilg, M., Lang, P., Schopf, R., Schwab, A., Utschik, H., Weißbrod, M., 2012. Floodplain restoration on the Upper Danube (Germany) by re-establishing water and sediment dynamics: a scientific monitoring as part of the implementation. River Systems 20, 55-70.

1050 Steiger, J., Tabacchi, E., Dufour, S., Corenblit, D., Peiry, J.-L., 2005. Hydrogeomorphic processes affecting riparian habitat within alluvial channel-floodplain river systems: a review for the temperate zone. River Res. Appl. 21, 719-738.

1053

Stella, J.C., Hayden, M.K., Battles, J.J., Piégay, H., Dufour, S., Fremier, A.K., 2011. The role of 1054 abandoned channels as refugia for sustaining pioneer riparian forest ecosystems. Ecosystems 14, 776-790.

Theiling, C.H., (1995). Habitat rehabilitation on the upper Mississippi River. Regul. River. 11, 227238.

1058

Toonen, W.H.J., Kleinhans, M.G., Cohen, K.M., 2012. Sedimentary architecture of abandoned channel fills. Earth Surf. Process. Landf. 37, 459-472. 